\title{
Immunotargeting of Nanocrystals by SpyCatcher Conjugation of Engineered Antibodies
}

\author{
Cassio C.S. Pedroso, ${ }^{1,+V i c t o r ~ R . ~ M a n n, ~}{ }^{1, \star}$ Kathrin Zuberbühler, ${ }^{2}$ Markus-Frederik Bohn, ${ }^{2}$ Jessica Yu, ${ }^{1}$ \\ Virginia Altoe, ${ }^{1}$ Charles S. Craik ${ }^{2} \&$ Bruce E. Cohen ${ }^{1,3 *}$ \\ ${ }^{1}$ The Molecular Foundry, and ${ }^{3}$ Division of Molecular Biophysics \& Integrated Bioimaging, Lawrence Berkeley National La- \\ boratory, Berkeley, CA 94720 \\ ${ }^{2}$ Department of Pharmaceutical Chemistry, University of California San Francisco, San Francisco, CA, 94143
}

\begin{abstract}
Inorganic nanocrystals such as quantum dots (QDs) and upconverting nanoparticles (UCNPs) are uniquely suited for quantitative live-cell imaging and are typically functionalized with ligands to study specific receptors or cellular targets. Antibodies $\mathrm{Ab}$ ) are among the most useful targeting reagents owing to their high affinities and specificities, but common nanocrystal labeling methods may orient $\mathrm{Ab}$ incorrectly, be reversible or denaturing, or lead to Ab-NP complexes too large for some applications. Here, we show that SpyCatcher proteins, which bind and spontaneously form covalent isopeptide bonds with cognate SpyTag peptides, can conjugate engineered $\mathrm{Ab}$ to nanoparticle surfaces with control over stability, orientation, and stoichiometry. Compact SpyCatcher-functionalized

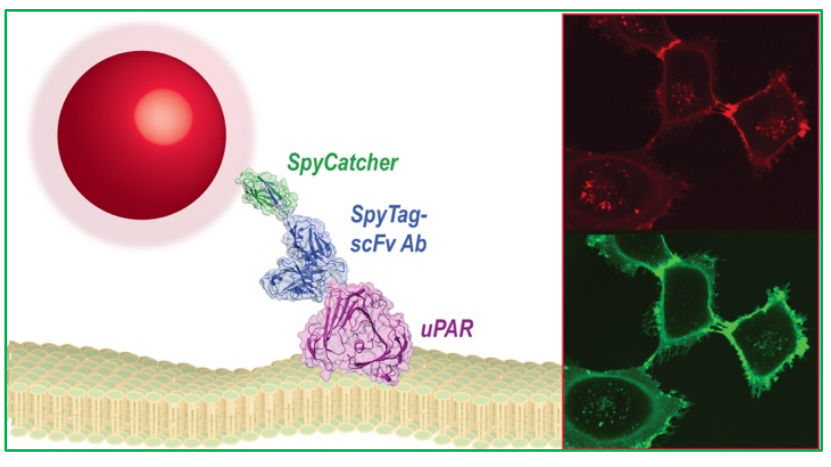
QDs and UCNPs may be labeled with short-chain variable fragment Ab (scFv) engineered to bind urokinase-type plasminogen activator receptors (uPAR) that are overexpressed in many human cancers. Confocal imaging of anti-uPAR scFv-QD conjugates shows the $\mathrm{Ab}$ mediates specific binding and internalization by breast cancer cells expressing uPAR. Time-lapse imaging of photostable scFv-UCNP conjugates show that Ab binding causes uPAR internalization with a $\sim 20$-minute half-life on the cell surface, and uPAR is internalized to endolysosomal compartments distinct from general membrane stains and without significant recycling to the cell surface. The controlled and stable conjugation of engineered Ab to NPs enables targeting of diverse receptors for live-cell study of their distribution, trafficking, and physiology.
\end{abstract}

The specific and sensitive detection of cell-surface markers is essential for understanding molecular signaling in both healthy and diseased cells. Cell surface receptors or other biomarkers are typically detected by antibody $(\mathrm{Ab})$ conjugates designed for fluorescence imaging or for targeting therapeutics. ${ }^{1,2} \mathrm{Ab}$ selection and engineering technologies have enabled design of these targeting proteins with high affinity and selectivity for a broad range of biomolecules, ${ }^{3}$ and novel $\mathrm{Ab}$ miniaturization and labeling strategies have found use in a range of imaging and biotechnology applications.,

$\mathrm{Ab}$ typically used for immunotargeting are large $(150 \mathrm{kDa})$ and highly polymorphic IgG with 2 identical antigen binding sites, which are spaced up to $17 \mathrm{~nm}$ apart in X-ray structures (Fig. 1A). ${ }^{6}$ Protein engineering has produced monovalent $\mathrm{Ab}$ constructs that are significantly smaller and retain antigen affinity and selectivity, including single chain variable fragments $(\mathrm{scFv})$ that are $25-30 \mathrm{kDa}$ and are often more amenable to expression and modification. 3 Numerous sidechain and carbohydrate bioconjugation reactions have been developed for synthesizing $\mathrm{Ab}$ conjugates, although some of these reactions have been shown to be reversible under physiological conditions $^{7-9}$ or to reduce Ab stability or affinity for ligand. ${ }^{10-12}$

Inorganic nanoparticles (NP) possess optical properties that make them particularly well-suited for live cell imaging. Compared to organic or protein-based fluorophores, semiconductor quantum dots (QDs) have larger optical cross-
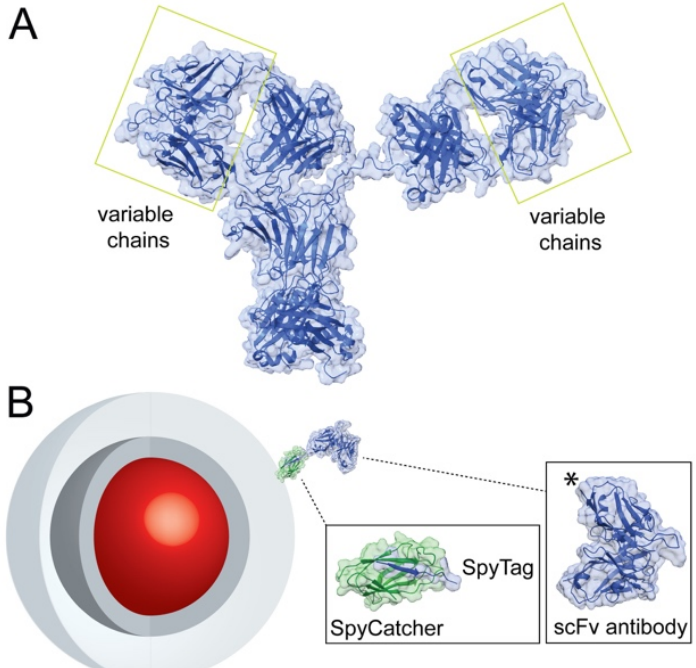

Figure 1. Design of nanoparticle-SpyCatcher-scFv antibody conjugates. A) Structure of full IgG Ab (adapted from ref. 6). Variable chains that bind antigens and are used to engineer miniaturized $\mathrm{scFv} \mathrm{Ab}$ are highlighted. B) Schematic of NP-SpyCatcher $\mathrm{scFv}$ Ab conjugates. Core/shell nanocrystals (red and dark gray), encapsulated in amphiphilic polymers (light gray), conjugated to a single-Cys SpyCatcher and SpyTag-scFv chimera. SpyCatcher-SpyTag and scFv $\mathrm{Ab}$ structures are adapted from refs. 23 and 24. The SpyTag peptide is added at the scFv $\mathrm{C}$ terminus, marked $(*)$ in the structure. 
sections, increased photostability, and broadband excitation spectra. ${ }^{13-16}$ Similarly, upconverting nanoparticles (UCNPs), which emit at visible wavelengths after absorption of multiple near infrared (NIR) photons, show no overlap with cellular autofluorescence, no measurable blinking or photobleaching at single-molecule powers, and can be imaged millimeters into tissue with exceptionally low laser fluences. ${ }^{17-20}$ For Ab-based imaging applications, inorganic NPs have adapted organic fluorophore bioconjugation reactions, ${ }^{14,21,22}$ but difficulties in controlling immunoconjugate size, stoichiometry, $\mathrm{Ab}$ orientation, and stability have limited the broad utility of AbNP conjugates. ${ }^{25-31}$ Newer covalent reactions that address these issues may be useful in expanding the scope of protein-NP conjugates in bioimaging, ${ }^{32}$ although these bimolecular reactions typically require higher reactant concentration than is possible for relatively large proteins and colloidal nanoparticles. One exception is the engineered split protein SpyCatcher/SpyTag, ${ }^{33,34}$ in which the components bind to one another with nanomolar affinity before forming stable isopeptide bonds, and which is emerging as a versatile system for the controlled and stable conjugation of proteins to NPs. ${ }^{35,36}$

The urokinase-type plasminogen activator receptor (UPAR) is a glycolipid-anchored cell membrane receptor critical to regulation of multiple cellular processes and has been found to have increased plasma membrane expression in many human cancer types. ${ }^{37-40}$ uPAR activation leads to its internalization in a complex multi-step process that is critical for its activity and which is not fully understood. ${ }^{37,41,42}$ Here, we describe the SpyCatcher-mediated synthesis of compact nanoparticle conjugates to anti-uPAR $\mathrm{scF}$ Ab for controlled and stable display of engineered $\mathrm{Ab}$ on nanoparticle surfaces. scFv-QD conjugates show specific internalization by uPAR-expressing cells, and live-cell imaging of scFv-UCNP enables extended tracking of uPAR complexes. We observe that $\mathrm{Ab}$ binding causes uPAR internalization with a $\sim 20$-minute half-life on the cell surface, and UPAR is internalized to endolysosomal compartments distinct from general membrane stains, and without significant recycling of $\mathrm{scFv}-\mathrm{UCNP}$ conjugates to the cell surface. SpyCatcher-mediated synthesis of nanoparticle immunoconjugates is applicable to multiple inorganic nanocrystals and to $\mathrm{Ab}$ that can be engineered to a $\mathrm{scFv}$, enabling a targeting strategy broadly applicable to receptors and other cellular proteins.

\section{RESULTS AND DISCUSSION}

Synthesis of SpyCatcher-functionalized nanoparticles. To synthesize stable and well-defined Ab-NP conjugates, we leveraged the capacity of SpyCatcher proteins on nanoparticle surfaces to conjugate SpyTag-bearing $\mathrm{Ab}$ under dilute, neutral conditions, ${ }^{36}$ without chemical modification of the $\mathrm{Ab}$. Inorganic nanocrystals, either 9-nm CdSe/CdS QDs ${ }^{15,16}$ or 19$\mathrm{nm}$ core/shell $\mathrm{NaYb}_{0.8} \mathrm{Er}_{0.2} \mathrm{~F}_{4}$ alloyed UCNPs (aUCNPs), ${ }^{19,43}$ were synthesized and characterized by TEM, XRD, dynamic light scattering (DLS), and optical methods (Figs. 2 and S1S3). ${ }^{15,19}$ To impart biocompatibility and resistance to aggregation in buffer without degrading optical properties, nanocrystals were encapsulated in amphiphilic copolymers $\left(\mathrm{PAOA}^{44}\right.$ or $\mathrm{PMAO}^{45}$; see Methods) bearing short PEGs and surface bioconjugation handles. DLS of aqueous aUCNPs shows no apparent aggregation and an increase in hydrodynamic diameter from 19 to $21 \mathrm{~nm}$ (Fig. 2). Conjugation to proteins was achieved through introduction of thiol-reactive groups at the NP surfaces, either by PAOA reaction with the amine-thiol crosslinker SM(PEG) $)_{2}$, or by PMAO reaction with pyridyldisulfide-ethylamine (PDEA) to display activated disulfides (Fig. S4). For conjugation to NP surfaces, a single Cys at Ser35 was introduced in an exposed SpyCatcher loop on the face opposing the SpyTag reaction site, and the protein was overexpressed in E. Coli. ${ }^{36}$ Conjugation to nanoparticle surfaces was analyzed by DLS, with hydrodynamic diameters increasing from 21 to $24 \mathrm{~nm}$ (Fig. 2D). The conjugation of S35C SpyCatcher was monitored by absorbance of the leaving group pyridine-2-thione, ${ }^{44,46}$ showing a stoichiometry of $\sim 20$ surface SpyCatcher proteins per aUCNP (Fig. S5).

Conjugation of engineered Ab to nanoparticles. The highaffinity 2G10 Ab against human uPAR was previously selected by phage screening of a naive human Fab library against native, folded uPAR. ${ }^{38,39,41}$ This 2 G10 heavy chain sequence has demonstrated monovalent dissociation constants in the $\mathrm{nM}$ range, selective binding to uPAR overexpressed HEK-293 cells, and inhibition of UPAR interaction with its uPA ligand. A single-chain variable fragment $(\mathrm{scFv})$ connecting both variable regions, $\mathrm{V}_{\mathrm{H}}$ and $\mathrm{V}_{\mathrm{L}}$, was constructed by standard cloning techniques, ${ }^{47}$ and a 3 mer spacer followed by a 13 mer SpyTag sequence $^{33}$ were added to the $\mathrm{C}$ terminus away from the uPAR binding site (Fig. 1). Expression in E. Coli produces a small $2 \mathrm{G} 10 \mathrm{scFv}$-SpyTag chimera $(32 \mathrm{kDa})$, whose reaction with free SpyCatcher is complete overnight at $4{ }^{\circ} \mathrm{C}$, as confirmed by gel electrophoresis and mass spectrometry (Fig. 2A-B). Conjugation of SpyTag- scFv to SpyCatcher-coated NPs is then
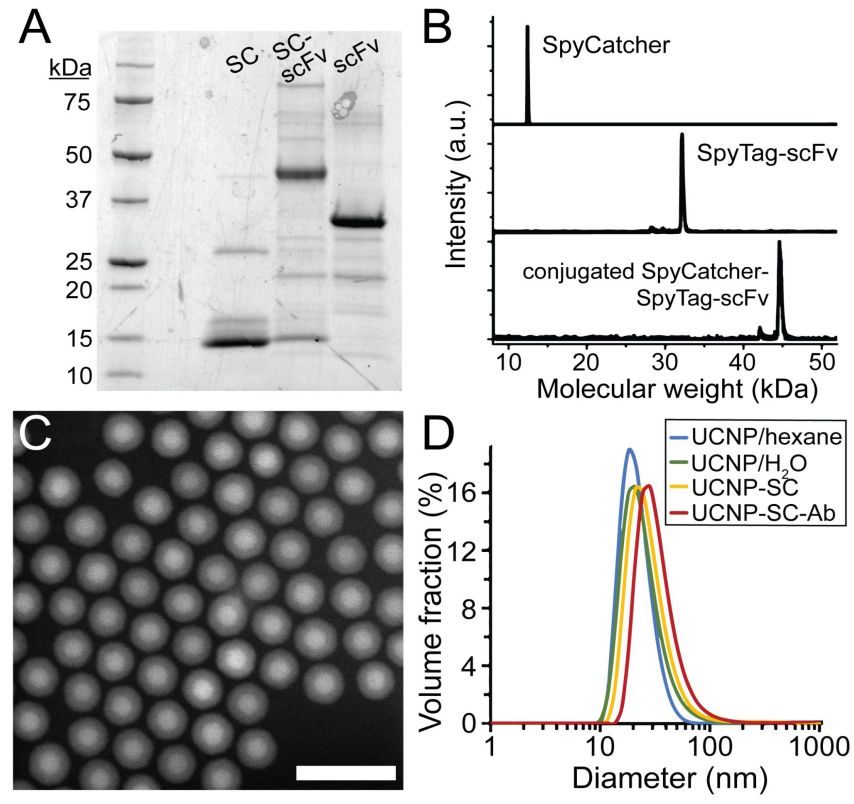

Figure 2. Synthesis of scFv-conjugated aUCNPs. (A) Expression and reaction of SpyCatcher (SC) and SpyTag-scFv Ab (ST-scFv), monitored by SDS-PAGE. Partially purified His-tagged $\mathrm{scFv}$ were incubated with an excess of SC. (B) MALDI mass spectra of purified SC and ST-scFv before and after conjugation. (C) Highangle annular dark field transmission electron micrograph of core/shell $\mathrm{NaEr}_{0.8} \mathrm{Yb}_{0.2} \mathrm{~F}_{4} @ \mathrm{NaY}_{0.8} \mathrm{Gd}_{0.2} \mathrm{~F}_{4}$ aUCNPs. Scale bar is 50 nm. (D) Diameters of nanoparticles determined by dynamic light scattering (DLS), of hydrophobic (blue), PMAO-encapsulated (teal), SpyCatcher-functionalized (yellow), and scFv-conjugated (red) UCNPs. Mean diameters $(n=5)$ are 19, 21, 24, and $28 \mathrm{~nm}$, respectively. 


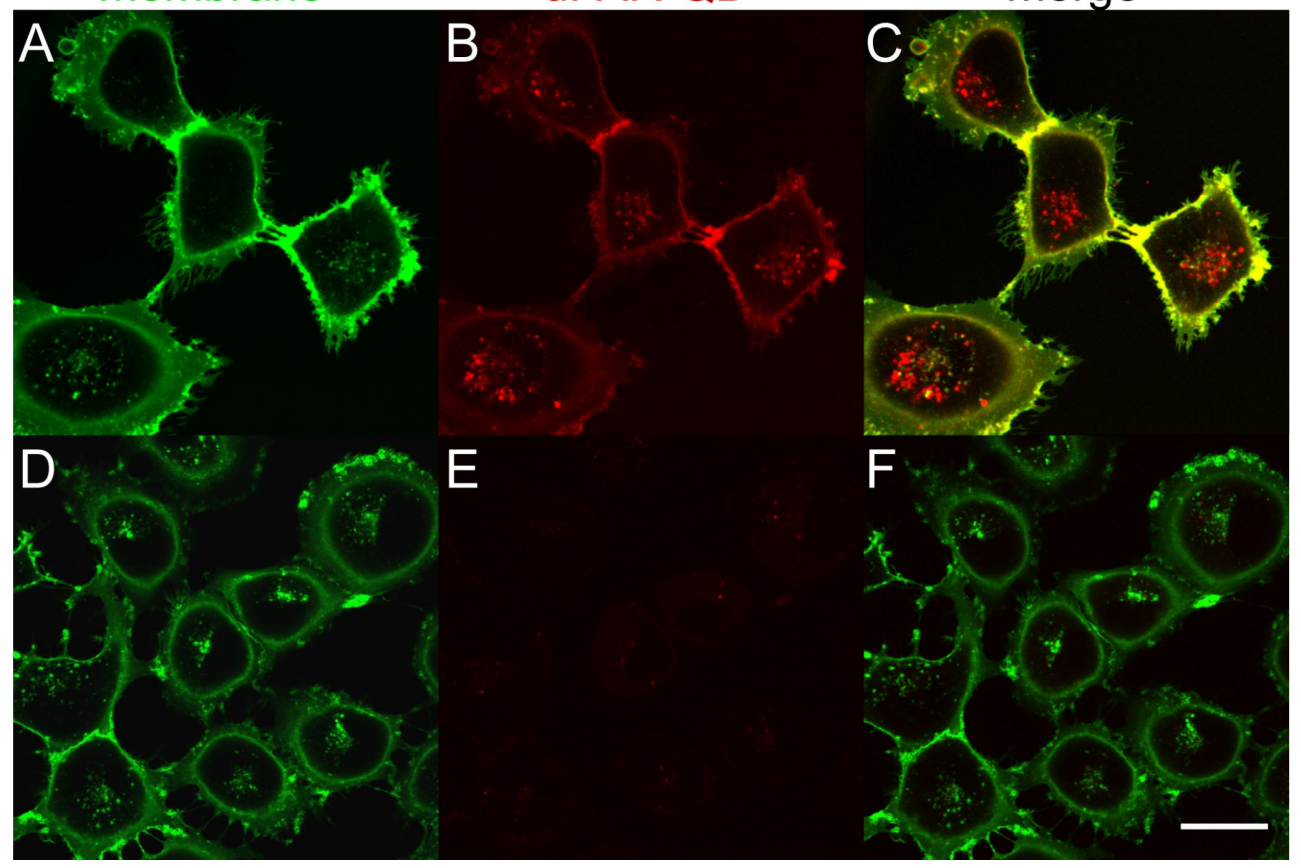

Figure 3. Specificity of anti-uPAR-QD internalization by uPAR-expressing breast cancer cells. Confocal images of live MDAMB-231 cells incubated with (A-C) scFv-QD conjugates $\left(610 \mathrm{~nm}\right.$ emission peak) for $60 \mathrm{~min}$ at $37^{\circ} \mathrm{C}$ or (D-F) SpyCatcher-QD conjugates without anti-uPAR scFv. (C,F) Overlay of WGA and anti-uPAR-QD emission. QDs were excited at $405 \mathrm{~nm}$ and emission collected from $605-690 \mathrm{~nm}$. AlexaFluor 488 was excited at $488 \mathrm{~nm}$ and emission collected from $495-575 \mathrm{~nm}$. Scale bar is $30 \mu \mathrm{m}$.

carried out in neutral buffer at room temperature over $16 \mathrm{~h}$, and monitored by DLS, showing a diameter increase from 24 to 28 $\mathrm{nm}$ for aUCNPs (Figure 2D). Because the SpyTag-SpyCatcher reaction goes almost to completion under these conditions, ${ }^{33,34}$ the average number of surface $\mathrm{scFv}$ was controlled by reaction stoichiometry ( $\sim 2 \mathrm{Ab}$ per QD and $\sim 10$ per aUCNP), and the immunoconjugates were used without further purification. The stoichiometry of scFv-aUCNP conjugation was measured using Trp fluorescence, and the average number of scFv per aUCNP was varied from 1 to 20 simply by control of concentrations of each (Fig. S6).

Live-cell imaging of scFv-QD conjugates. To determine whether Ab conjugated through NP surface-bound SpyCatcher proteins can target their antigens in live-cell imaging, we examined whether MDA-MB-231 cells, a breast cancer cell line that express high levels of uPAR receptors, ${ }^{41}$ would selectively internalize 2G10 scFv-NP immunoconjugates. Cells were incubated with scFv-functionalized QDs for 1 hour at $37^{\circ} \mathrm{C}$, followed by counterstain with membrane lectin-binding wheat germ agglutinin (WGA), and then characterized by live-cell confocal microscopy (Fig 3). The 2G10 scFv-QDs are rapidly internalized, and cells continue to show well-defined filopodia, actin-rich protrusions from the plasma membrane; ${ }^{48}$ the persistence of these structures even in the absence of extracellular matrix (e.g., fibronectin or collagen) is suggestive that the QD immunoconjugates are not detrimental to cell health. ${ }^{49}$ Internalized uPAR QDs and WGA show little or no co-localization (Fig. 3C), possibly owing to the sequential timing of labeling. QDs displaying SpyCatcher but without scFv show little attachment to the cell surface or internalization after incubation (Fig. 3D-F). Taken together, these results indicate that the $2 \mathrm{G} 10 \mathrm{scFv}$ remains active and selective for $\mathrm{UPAR}$ once conjugated to a nanoparticle surface, and the scFv-QD triggers a uPAR internalization sequence similar to native ligands. ${ }^{50,51}$

Tracking UPAR internalization kinetics with scFv-UCNP conjugates. To better understand the kinetics of ligand-mediated internalization of uPAR, we synthesized and imaged scFv-UCNP conjugates for time-lapse live-cell imaging. Because UCNPs do not photobleach, ${ }^{52,53}$ are unaffected by cellular components, ${ }^{18}$ and have no measurable overlap with the excitation/emission of cellular autofluorescence, ${ }^{17}$ they offer a more quantitative method for tracking receptor trafficking than conventional fluorophores. Core/shell $\mathrm{Yb}^{3+} / \mathrm{Er}^{3+}$ aUCNPs were synthesized for optimized brightness under $980 \mathrm{~nm}$ scanning continuous-wave laser excitation, ${ }^{19}$ and microscopy conditions were optimized by varying laser intensity, pinhole size, image resolution, pixel size, scan speed and area, and detector gain. The 980-nm excitation intensity, $10^{5}$ $\mathrm{W} / \mathrm{cm}^{2}$, shows no apparent phototoxicity during confocal imaging, consistent with previous single- UCNP tracking studies. ${ }^{18}$ The scan rate proved to be a critical parameter, with bidirectional scan mode speeds of $180 \mu \mathrm{sec} /$ pixel slow enough to afford a strong signal-tonoise ratio (SNR) given the $\mu \mathrm{sec}$ decay times of aUCNP phosphoresence, ${ }^{54}$ but fast enough to capture physiological events without significant blurring. This optimization of upconverting fast scanning confocal parameters affords roughly 2-3 orders of magnitude increase in SNR compared to standard fluorescence confocal imaging parameters (compare Fig. 4 with Fig. S7).

MDA-MB-231 cells were pre-incubated with $2 \mathrm{G} 10 \mathrm{scFv}-$ aUCNPs at $13{ }^{\circ} \mathrm{C}$ to minimize endocytosis, followed by imaging at $37{ }^{\circ} \mathrm{C}$ to track internalization under physiological conditions (Fig. 4 and Supplementary movie 1, green channel). Initial surface staining is followed by the appearance of small puncta at $10 \mathrm{~min}$, which then increase in number and intensity, and are accompanied by a near-complete loss of plasma membrane emission. A lipophilic organic fluorophore that non-specifically intercalates 


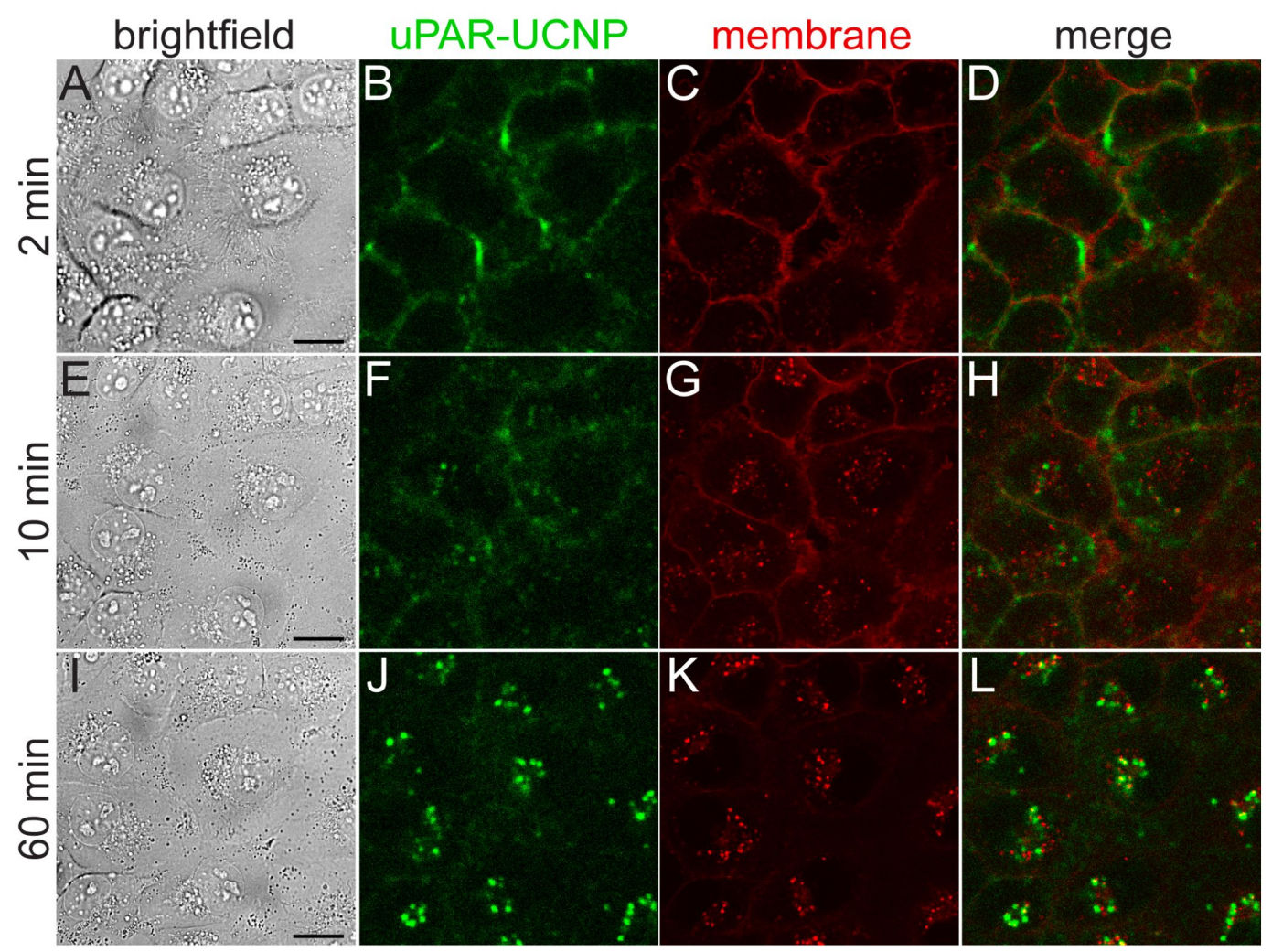

Figure 4. Kinetics of anti-uPAR scFv-UCNP internalization in breast cancer cells. Live MDA-MB-231 cells treated with $2 \mathrm{G} 10 \mathrm{scFv}-$ UCNP immunoconjugates at $37^{\circ} \mathrm{C}$, imaged by: (A,E,I) brightfield; (B,F,J) upconverted confocal microscopy for anti-uPAR-UCNP imaging; and $(\mathrm{C}, \mathrm{G}, \mathrm{K})$ standard confocal microscopy for lipophilic fluorophore Cellmask Orange. UCNPs were excited at $980 \mathrm{~nm}$ and emission collected from $380-750 \mathrm{~nm}$. Cellmask Orange was excited at $561 \mathrm{~nm}$ and emission collected from $495-575 \mathrm{~nm}$. (D,H,L) Overlay of antiuPAR-UCNP and membrane emission. Frames $2 \mathrm{~min}$ (A-D), $10 \mathrm{~min}(\mathrm{E}-\mathrm{H})$, and $60 \mathrm{~min}$ (I-L) of full 70-min time lapse (Supplementary movie 1) are shown here. Scale bars are $20 \mu \mathrm{m}$.

in the plasma membrane (Fig. 4, red channel) is similarly internalized, ${ }^{55}$ but without significant overlap with the scFvaUCNPs. SpyCatcher- aUCNP conjugates without $2 \mathrm{G} 10 \mathrm{scFv}$ show modest cell membrane attachment after pre-incubation, with $\sim 25 \%$ the emission intensity of Ab conjugates (Fig. S8), and fewer, dimmer puncta are observed (Supplementary movie 2).

To quantify these differences in internalization, we used ImageJ software ${ }^{56}$ to analyze images for $\mathrm{scFv}$-UCNP and membrane stain distribution, calculating internalized and surface fractions (Figs. 5 and S9). Over half of the scFv-UCNPs are internalized after $20 \mathrm{~min}$ at $37^{\circ} \mathrm{C}$, and this reaches almost $75 \%$ internalization, with no apparent recycling to the cell surface. The lipophilic membrane stain is internalized more slowly and to a lesser extent than the scFv-UCNP. Limitations of this image analysis may include difficulties in distinguishing plasma membrane emission from that of endosomes residing just below the surface, low precision in identifying the plasma membrane in ImageJ, out-of-plane emission, and organic fluorophore photobleaching. ${ }^{55}$

Challenges of synthesizing nanocrystal immunoconjugates. The ubiquity of antibodies in cell imaging arises from the ability to select specific, high-affinity probes against a wide range of receptors and other cellular components. $^{1,3}$ Advances in $\mathrm{Ab}$ selection methods and engineering have both expanded the range of possible targets and enabled the development of miniaturized Ab designs with specific conjugation handles that avoid some of the pitfalls of traditional Ab labeling techniques, such as breakdown under physiological conditions, either for non-covalent ${ }^{28-30,57}$ or equilibrium covalent ${ }^{7,9,32}$ interactions. Common labeling techniques that require chemical modification of the $\mathrm{Ab}$, such as oxidation or reduction, also run the risk of diminishing Abligand affinity or $\mathrm{Ab}$ stability and need to be evaluated on a

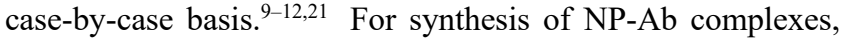
most reactions adapted from organic fluorophore chemistry, such as lysine sidechain modification, are far more difficult to control with the multivalent reactivity of both $\mathrm{Ab}^{11,58}$ and NP surfaces, ${ }^{14,44}$ which presents the risk of significant aggregation. Similarly, nonspecific adsorption of full $\mathrm{Ab}$ to NP surfaces exposes their Fc regions, which have high affinity for off-target Fc receptors. ${ }^{59}$ Common methods that avoid these problems include streptavidin coating of NP surfaces, which are then recognized with a biotinylated secondary antibody to a primary antigen-specific antibody, although this results in complexes $>40 \mathrm{~nm}$ in diameter that dwarf the size of the typical protein target and leave the large complexes prone to aggregation or unable to reach their targets. ${ }^{15,25}$

Newer reactions designed for site-specific conjugation of drugs or fluorophores can overcome these issues, ${ }^{12,32,51}$ but those that rely on diffusion for reactants to interact are constrained by inherent limits on NP and Ab concentrations (i.e., low $\mu \mathrm{M}$, well below the $\mathrm{mM}$ concentrations typical for bimolecular 


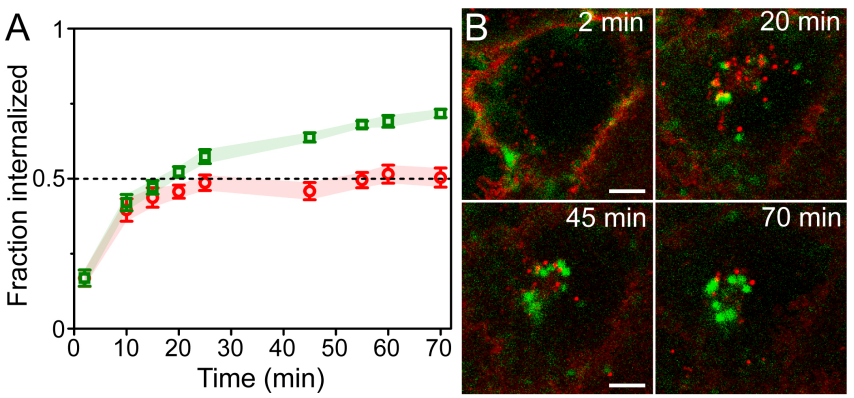

Figure 5. Differences of internalization and recycling between anti-uPAR scFv-UCNPs and a lipophilic membrane stain in breast cancer cells. (A) Fraction internalized of $2 \mathrm{G} 10 \mathrm{scFv}-\mathrm{UCNP}$ immunoconjugates in live MDA-MB-231 cells during incubation at $37^{\circ} \mathrm{C}$ (mean $\pm \mathrm{SEM} ; n=6$ cells). (B) Confocal images of antiuPAR-UCNPs (green squares) and lipophilic membrane fluorophore (red circles) in live MDA-MB-231 cells showing differences in intracellular localization between probes. Details from frames at 2, 20, 45 and $70 \mathrm{~min}$ of full 70-min time-lapse (Supplementary movie 1) are shown. Scale bars are $10 \mu \mathrm{m}$.

reactions), as well as slower diffusion rates compared to small organics. Our initial attempts to use aldehyde-reactive PictetSpengler reagents ${ }^{8}$ conjugated to UCNP surfaces showed no apparent conjugation with aldehyde-tagged antibodies ${ }^{51}$ (not shown). In contrast, SpyTag peptides bind to SpyCatcher proteins with low $\mathrm{nM}$ affinities before isopeptide bond formation, ${ }^{23}$ enabling these irreversible reactions to proceed nearly to completion at low concentrations of both $\mathrm{Ab}$ and NPs. ${ }^{36}$ The stability of the SpyCatcher-SpyTag isopeptide bond is critical for extended imaging experiments, as some common methods of $\mathrm{Ab}$ attachment have been shown to dissociate or reverse under live-cell imaging conditions, including those based on electrostatic, ${ }^{28-30,60}$ biotinavidin, ${ }^{57}$ or protein-protein interactions, ${ }^{61}$ as well as aldehydebased oxime or hydrazide bonds. ${ }^{7,8}$ Unlike many methods developed specifically for protein functionalization of NPs, ${ }^{13,14,27,31,60,61}$ SpyCatcher-mediated bioconjugation does not depend on a specific nanocrystal surface chemistry, making it compatible with any hydrophobic nanocrystal passivated with amphiphilic polymers, which have found use for improving both colloidal stability and optoelectronic properties of diverse hydrophobic nanocrystals. ${ }^{15,16,44,45}$

Antibody engineering enables improved nanoparticle conjugation. $\mathrm{Ab}$ engineering efforts over the last 2 decades have demonstrated that selective and high-affinity binding sequences against a variety of antigens can be selected and then subcloned into $\mathrm{Ab}$ scaffolds to create stable $\mathrm{Ab}$ with non-natural properties, and that this requires only basic recombinant DNA technology. ${ }^{3}$ Unlike naturally occurring IgG $\mathrm{Ab}$, which are $>15$ $\mathrm{nm}$ along their longest axes, ${ }^{6} \mathrm{scFv} \mathrm{Ab}$ are $2-3 \mathrm{~nm}$ in diameter, ${ }^{24}$ can readily be expressed in $E$. coli, and do not have Fc domains that bind to macrophages, lymphocytes, and other cells expressing Fc receptors.$^{59} \mathrm{~A}$ key advantage of recombinant $\mathrm{Ab}$ technology is the ease of introducing C-terminal modifications for various applications, ranging from purification (e.g., hexahistidine, $m y c$ tags), to valency engineering, to biotechnology applications such as drug conjugation and enzyme fusion. ${ }^{62-64}$ Here, the Cterminal SpyTag enables stable, oriented, and stoichiometric self-assembly and -reaction to form scFv-UCNP conjugates, which allows long-term tracking of the fate of UPAR without concern that the Ab may dissociate from the UCNP in the complex cellular environment. The generality of SpyCatcher-mediated conjugation of $\mathrm{scFv} \mathrm{Ab}$ to NP surfaces, unlimited by either
Ab target or NP chemistry, suggests potential in a variety immunotargeting applications, ranging from deeply subwavelength NIR imaging ${ }^{65}$ to whole animal imaging. ${ }^{19,66}$

Quantitative bioimaging with upconvertng nanoparticles. UCNPs differ from organic and protein fluorophores in significant ways that address some of the confounding factors in quantitative image analysis, such as loss of probe signal to photobleaching, uneven distribution of cellular autofluorescence, bleed-through between channels in multicolor imaging, and changes in cell health during live cell imaging. UCNPs have shown complete resistance to photobleaching, even under extreme conditions, ${ }^{52,53}$ they have no measurable NIR-excited emission overlap with fluorophores or cellular autofluorescence, ${ }^{17,18}$ and are excited at NIR wavelengths that are significantly less phototoxic to cells than visible wavelengths. ${ }^{18,19}$ However, imaging UCNPs by scanning microscopy presents unique challenges owing to the relative inefficiency and longer lifetimes of multiphoton $\mathrm{Ln}^{3+}$ upconversion. ${ }^{19,54,67}$ The aUCNPs in this study have been optimized for both higher quantum yields and shorter luminescence lifetimes, ${ }^{19}$ and confocal parameters also needed to be optimized for fast scanning under non-phototoxic 980-nm excitation intensities (ca. $\left.10^{5} \mathrm{~W} / \mathrm{cm}^{2}\right)^{18}$ to account for the trade-off between SNR and the kinetic resolution needed for live-cell processes. uPAR localization is limited primarily by the diffraction limit ( 300 nm for UCNP wavelengths ${ }^{65}$ ), which makes it difficult to pinpoint the exact plasma membrane boundary or to distinguish between receptors on the plasma membrane from those sitting in endosomes just inside the surface. Previous live-cell UCNP imaging has relied on exceptionally high intracellular UCNP concentrations, by microinjection or extended incubations, ${ }^{68,69}$ or on using relatively large $(>50 \mathrm{~nm}) \mathrm{UCNPs}^{70}$ For receptor tracking experiments, UCNP concentration is limited by receptor surface expression levels, and large UCNPs run the risk of altering trafficking patterns or may be too large to reach their targets. ${ }^{25}$

Live-cell imaging of UPAR trafficking. The primary function of the UPAR system is to degrade the proximal extracellular matrix, making the density of active receptors on the cell surface critical to uPAR function. ${ }^{40}$ uPAR surface density is controlled by the endolysosomal pathway, which internalizes and then sorts activated UPAR complexes, either for recycling to the cell surface or degradation in lysosomes. A ligand-induced clathrin-dependent endocytic pathway internalizes a complex of UPAR with its soluble ligand UPA and other membrane-associated proteins. ${ }^{71}$ These are subject to proteolysis or glycolipid cleavage to dissociate the components and produce soluble forms of uPAR. ${ }^{50}$ Alternatively, a constitutive clathrin- and ligand-independent internalization has been found to contribute to rapid UPAR endocytosis and recycling. ${ }^{72}$ In both of these processes, uPAR is returned to the cell surface without its ligands, which are dissociated and sent to lysosomes. ${ }^{71}$ In this study, the intracellular localization of uPAR-specific UCNPs is distinct from a lipophilic dye that intercalates non-specifically in the plasma membrane and is subject to constitutive membrane recycling (Figs. 4, 5) ${ }^{73}$ suggesting that UPAR internalization is induced by ligand binding rather than constitutive in MDA-MB-231 cells. The internalization kinetics of the scFv-UCNP complex with uPAR are similar to those observed for uPA-uPAR complexes, ${ }^{50,74}$ which also suggests a ligand-induced mechanism, and that the 2G10 anti-uPAR scFv evokes similar internalization responses as the endogenous ligand $\mathrm{uPA}$. There appears to be no recycling to the plasma membrane of scFv-UCNP during the 70-min experiment (Fig. 5), which may reflect its dissociation from 
uPAR and targeting to lysosomes, where the UCNPs remain luminescent, or differences in trafficking between uPA-uPAR and Ab-uPAR complexes. The photostability and chemical stability of scFv-UCNP conjugates throughout the endolysosomal pathway, from plasma membrane to lysosomes, makes them particularly useful for quantitative live-cell trafficking studies.

\section{CONCLUSION}

We have demonstrated that SpyCatcher proteins can attach engineered SpyTag-Ab fusions to different nanoparticle surfaces with control over stability, orientation, and stoichiometry. scFvconjugated QDs and UCNPs are specific in binding target uPAR, a key protein in the development of many human cancers, and are selectively internalized by cultured cancer cells overexpressing

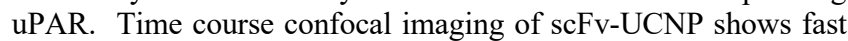
uptake where at least half of the available immunoconjugates are internalized after 20 min incubation and accumulation over time with no apparent recycling to the cell surface. This strategy for specific and stable conjugation of antibodies to NPs as compact probes may be extended to many other engineered $\mathrm{Ab}$ fragments quantitative live-cell imaging of a range of biological targets.

\section{MATERIALS AND METHODS}

Chemicals and materials. Erbium chloride hydrate $\left(\mathrm{ErCl}_{3} \cdot \mathrm{xH}_{2} \mathrm{O}, 99.999 \% \mathrm{Er}\right)$ was purchased from Strem Chemicals; poly(maleic anhydride-alt-1-octadecene) (PMAO) was purchased from Polysciences; 2-(2-(2-methoxyethoxy)ethoxy)ethanamine (m-PEG ${ }_{3}$-amine) was purchased from Aurum Pharmatech; and $\mathrm{SM}(\mathrm{PEG})_{2}$ was purchased from ThermoFisher. Mutagenesis kits and competent cells were purchased from New England Biolabs. Custom DNA oligos were purchased from Genscript. Plasmids were procured from Addgene, and cell lines were purchased from ATCC. All other reagents and chemicals were purchased from MilliporeSigma and used without further purification.

Aqueous passivation of CdSe/CdS QDs. CdSe/CdS QDs with emission maxima of $610 \mathrm{~nm}$ were synthesized as described ${ }^{15,44}$ and dispersed in hexane with $1 \%(v / v)$ oleic acid to $8 \mu \mathrm{M}$, as determined by first exciton absorbance. PAOA polymer $(20 \mathrm{mg}, 6.25 \mu \mathrm{mol}$, 3000-fold molar excess over QDs) was dissolved in $1 \mathrm{~mL}$ of $\mathrm{MeOH}$ and $19 \mathrm{~mL}$ of $\mathrm{CHCl}_{3}$. QDs in hexane $(250 \mu \mathrm{L}$ of $8 \mu \mathrm{M}, 2.0 \mathrm{nmol})$ were added with stirring, and the solvents were removed under a gentle stream of $\mathrm{N}_{2}$ overnight. The dry QD/polymer residue was then resuspended in $15 \mathrm{~mL}$ of $200 \mathrm{mM}$ sodium bicarbonate buffer, $\mathrm{pH}$ 8.0. This suspension was sonicated for $30 \mathrm{~min}$, heated in an 80 ${ }^{\circ} \mathrm{C}$ water bath for $60 \mathrm{~min}$, slowly cooled in the bath to room temperature, and then sonicated for $30 \mathrm{~min}$. Excess polymer was removed by spin dialysis (Amicon Ultra15, $50 \mathrm{kDa}$ MWCO), washing with $3 \times 15 \mathrm{~mL}$ of $100 \mathrm{mM}$ HEPES, $\mathrm{pH} 7.8$. The retentate was diluted to $1 \mathrm{~mL}$ with HEPES buffer and centrifuged at 16100 $\mathrm{x} g$ for $5 \mathrm{~min}$ to remove residual polymer and insoluble aggregates. Aqueous QD dispersions were stored under ambient conditions.

Synthesis of core UCNPs. The $\beta$-phase $\mathrm{NaYb}_{0.8} \mathrm{Er}_{0.2} \mathrm{~F}_{4}$ nanocrystals were synthesized with minor modifications of the methodology previously described. ${ }^{19,52} \mathrm{YbCl}_{3} \cdot 6 \mathrm{H}_{2} \mathrm{O}(0.24 \mathrm{mmol}$, $93 \mathrm{mg}$ ), $\mathrm{ErCl}_{3} \cdot \mathrm{xH}_{2} \mathrm{O}$ (0.06 mmol, $23 \mathrm{mg}$ ), oleic acid (OA, $3.25 \mathrm{~g}$ ) and 1-octadececene (ODE, $4 \mathrm{~mL}$ ) were added into a 50-mL 3-neck flask. The precursors were then heated to $110^{\circ} \mathrm{C}$ under vacuum and stirred for $45 \mathrm{~min}$, yielding Ln oleates in a clear, homogeneous solution. The flask was filled with $\mathrm{N}_{2}$ and cooled to room temperature. Sodium oleate $(1.25 \mathrm{mmol}, 382 \mathrm{mg}), \mathrm{NH}_{4} \mathrm{~F}(2.0$ mmol, $74 \mathrm{mg}$ ), and ODE (3 $\mathrm{mL})$ were added, the mixture was stirred under vacuum at room temperature for $20 \mathrm{~min}$ and then heated at $305{ }^{\circ} \mathrm{C}$ under $\mathrm{N}_{2}$ for $45 \mathrm{~min}$. The heating mantle was removed and a strong stream of air was used to cool the reaction flask to room temperature. To purify the UCNPs, the suspension was transferred to a $50 \mathrm{~mL}$ centrifuge tube, and $15 \mathrm{~mL}$ of EtOH was added to precipitate the nanocrystals. The tube was centrifuged at $3000 \times g$ for $5 \mathrm{~min}$ forming a white pellet. The supernatant was disposed and the solid was sonicated in $n$-hexane $(5 \mathrm{~mL})$ to disperse the nanocrystals. The dispersion was centrifuged at $3000 \times g$ for 3 min and transferred to a new tube leaving behind insoluble impurities. The purification cycle was repeated one more time, and then the nanocrystals were stored in $10 \mathrm{~mL}$ of $n$-hexane with $0.2 \%$ $(v / v)$ oleic acid under ambient conditions.

Synthesis of core/shell UCNPs. Epitaxial $\mathrm{NaY}_{0.8} \mathrm{Gd}_{0.2} \mathrm{~F}_{4}$ shells were grown on $\beta-\mathrm{NaYb}_{0.8} \mathrm{Er}_{0.2} \mathrm{~F}_{4}$ cores using a layer-by-layer method $^{19}$ in WANDA, a nanocrystal synthesis robot at the Molecular Foundry. ${ }^{75}$ A precursor solution of $0.10 \mathrm{M}$ oleates was prepared by heating $\mathrm{YCl}_{3}(0.8 \mathrm{mmol}, 156 \mathrm{mg})$ and $\mathrm{GdCl}_{3}(0.2$

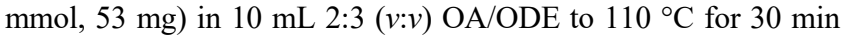
under vacuum and $160{ }^{\circ} \mathrm{C}$ for about $30 \mathrm{~min}$, until the solution became clear. Then, the solution was cooled to $110^{\circ} \mathrm{C}$ and purged under vacuum for $30 \mathrm{~min}$. A $0.20 \mathrm{M}$ sodium trifluoroacetate (NaTFA) solution with OA was prepared in a separate flask by stirring NaTFA ( $2 \mathrm{mmol}, 272 \mathrm{mg}$ ), $5 \mathrm{~mL}$ OA, and $5 \mathrm{~mL}$ ODE under vacuum at room temperature for $2 \mathrm{~h}$ ensuring that no solid remained. Purified core UCNPs in $n$-hexane $(15 \mathrm{nmol})$ were stirred under $\mathrm{N}_{2}$ stream to evaporate the solvent and redispersed in $4 \mathrm{~mL}$ of OA and $6 \mathrm{~mL}$ of ODE. Then, the reaction was carried out using a robotic WANDA protocol under air-free conditions. The core UCNP dispersion was stirred and heated to $280{ }^{\circ} \mathrm{C}$ at $20^{\circ} \mathrm{C} / \mathrm{min}$. Then, $0.10 \mathrm{M}$ Ln-OA and $0.20 \mathrm{M}$ NaTFA-OA solutions were injected in alternating cycles into the reaction at $17 \mu \mathrm{L} / \mathrm{s}$. Every cycle began with the Ln-OA addition, followed by the Na-TFA-OA addition, waiting $20 \mathrm{~min}$ between each injection to form a single $0.5-\mathrm{nm}$ unit cell layer. After the last injection, the dispersion was stirred for an additional $30 \mathrm{~min}$ at $280^{\circ} \mathrm{C}$ and cooled rapidly to room temperature. Core/shell UCNPs were purified and stored using the procedure described for core UCNPs.

Crystalline structure determination by $X$-ray powder diffraction. All oleate-capped nanocrystals were characterized by X-ray powder diffraction on a Bruker AXS D8 Discover GADDS $\mathrm{X}$-ray diffractometer operating with $35 \mathrm{kV} / 40 \mathrm{~mA}$ Co $\mathrm{K} \alpha(\lambda=$ $1.78897 \AA$ ) radiation. For XRD samples, $200 \mu \mathrm{L}$ of a UCNPs stock solution in $n$-hexane was spotted onto a glass coverslip and allowed to air dry completely until an opaque white film formed. All $\mathrm{NaLnF}_{4}$ nanocrystals were found to be pure hexagonal $\beta$ phase.

Synthesis of 2-(2-pyridyldisulfide)ethylamine (PDEA). Aldrithiol-2 (2,2'-Dipyridyldisulfide, $20.0 \mathrm{mmol}, 4.41 \mathrm{~g})$ was dissolved in $20 \mathrm{~mL}$ of $\mathrm{MeOH}$ with $0.8 \mathrm{~mL}$ of glacial $\mathrm{AcOH}$ in a 300 $\mathrm{mL}$ round-bottom flask. Cysteamine- $\mathrm{HCl}(10.0 \mathrm{mmol}, 1.14 \mathrm{~g})$ dissolved in $20 \mathrm{~mL}$ of $\mathrm{MeOH}$ was added dropwise over $1 \mathrm{~h}$ to the vigorously mixing flask and stirred for $16 \mathrm{~h}$ under $\mathrm{N}_{2}$ atmosphere. $\mathrm{MeOH}$ was removed by rotary evaporation, and the yellow oil product was washed twice with $50 \mathrm{~mL}$ of dry, ice-cooled $\mathrm{Et}_{2} \mathrm{O}$. The oil was dissolved in $10 \mathrm{~mL}$ of $\mathrm{MeOH}$ and precipitated by addition of $200 \mathrm{~mL}$ of cold $\mathrm{Et}_{2} \mathrm{O}$. The flask was stored at $-20{ }^{\circ} \mathrm{C}$ for $36 \mathrm{~h}$ to ensure full precipitation. The pale-yellow solid was vacuum filtered, rinsing with $3 \times 50 \mathrm{~mL}$ of dry ice-cold $\mathrm{Et}_{2} \mathrm{O}$, and left under vacuum for $20 \mathrm{~min}$ to remove residual solvent, giving $2.02 \mathrm{~g}(93 \%$ yield) of PDEA. ${ }^{1} \mathrm{H}$ NMR (500 MHz, $\mathrm{CD}_{3} \mathrm{OD}$ ): $\delta 9.39$ (broad s, $3 \mathrm{H}), 9.29(\mathrm{~d}, 1 \mathrm{H}), 8.45(\mathrm{t}, 1 \mathrm{H}), 8.32(\mathrm{~d}, 1 \mathrm{H}), 7.97(\mathrm{t}, 1 \mathrm{H}), 3.92(\mathrm{~m}$, $4 \mathrm{H})$. Mass spectrum, $\mathrm{C}_{7} \mathrm{H}_{11} \mathrm{~N}_{2} \mathrm{~S}_{2}\left(\mathrm{MH}^{+}\right)$calculated: 187.0 ; found: 187.2.

Aqueous passivation of core/shell UCNPs. PMAO polymer ${ }^{45}$ ( $2 \mathrm{mg}, 0.8$ monomer units per $\mathrm{nm}^{2}$ of UCNP surface area) was dissolved in $1 \mathrm{~mL}$ of acetone, $14 \mathrm{~mL}$ of $\mathrm{CHCl}_{3}$ was added, and the mixture was quickly sonicated to obtain a homogeneous solution. Approximately $200 \mu \mathrm{L}$ of $0.5 \mu \mathrm{M}$ core/shell UCNPs $(0.1$ 
nmol) in $n$-hexane was added to the polymer dispersion. The solution was stirred overnight under a gentle stream of $\mathrm{N}_{2}$ until the complete evaporation of the solvents. The UCNP/polymer residue was then resuspended in $15 \mathrm{~mL}$ of $100 \mathrm{mM}$ sodium borate buffer, pH 8.6 with 1:99 ratio of PDEA $(1.27 \mathrm{mg}, 5.7 \mu \mathrm{mol})$ to $2-(2-(2-$ methoxyethoxy)ethoxy)-ethylamine (92 $\mu \mathrm{L}, 564 \mu \mathrm{mol})$. The reaction flask was sonicated during $4 \mathrm{~h}$ at a water bath. The excess polymer was removed with $100 \mathrm{mM}$ HEPES, $\mathrm{pH} 7.4$, by five rounds of centrifugal dialysis (Amicon Ultra-15, $100 \mathrm{kDa}$ MWCO). Aqueous dispersions of UCNPs were further purified to remove excess polymer by dialysis (Spectra-Por Float-A-Lyzer G2, $10 \mathrm{~mL}, 100$ $\mathrm{kDa} \mathrm{MWCO}$ ) and concentrated by spin dialysis (Amicon Ultra-15, $100 \mathrm{kDa}$ MWCO) to a final $1 \mathrm{~mL}$ dispersion in $20 \mathrm{mM}$ HEPES buffer, $\mathrm{pH}$ 7.4. The final concentration was determined as $100 \mathrm{nM}$ by an emission versus concentration curve measured for the parent hydrophobic UCNPs.

Emission of UCNPs dispersions. Low-power upconverted emission spectra were measured from aqueous UCNPs diluted at $25 \mathrm{nM}$ in $20 \mathrm{mM}$ HEPES, $\mathrm{pH}$ 7.4. The spectra were performed in FLS980 Spectrometer (Edinburg Instruments) equipped with a 980nm laser (CrystaLaser) from 495 to $800 \mathrm{~nm}$, using a 2-nm slit bandwidth and $1 \mathrm{~s}$ integration times. Spectra were corrected for the sensitivity of the detector using a calibrated light source.

scFv antibody cloning. The anti-uPAR antibody $2 \mathrm{G} 10$ was previously discovered from a highly diverse and naïve human Fab phage display library. ${ }^{38}$ Expression plasmids were cloned by standard PCR methods and assembled by Gibson assembly. To generate the $2 \mathrm{G} 10 \mathrm{scFv}$-SpyTag construct, $\mathrm{V}_{\mathrm{H}}$ and $\mathrm{V}_{\mathrm{L}}$ domains of 2G10 were cloned into the expression vector pSYN1 (kindly provided by Dr. James D. Marks, UCSF) using cutting sites NcoI and NheI for $\mathrm{V}_{\mathrm{H}}$ and BssHII and NotI for $\mathrm{V}_{\mathrm{L}}$. SpyTag (AHIVMVDAYKPTK) ${ }^{33}$ was added to the C-terminus of the $\mathrm{V}_{\mathrm{L}}$ domain with a GSG linker sequence creating a -GSG-SpyTag-Myc$\mathrm{His}_{6}$ carboxy terminus.

SpyCatcher and scFv antibody expression. Plasmids encoding SpyCatcher and 2G10-SpyTag scFv were transformed into the $E$. coli expression cell line BL21(DE3) (MilliporeSigma) for heterologous protein expression. Single colonies from agar plates were used to inoculate cultures of LB broth $(25 \mathrm{~mL})$ containing ampicillin $(100 \mu \mathrm{g} / \mathrm{mL})$ and grown at $37^{\circ} \mathrm{C}$ overnight $(250 \mathrm{rpm})$. This starter culture was then used to inoculate $2 \times 500 \mathrm{~mL}$ Terrific Broth cultures containing ampicillin $(100 \mu \mathrm{g} / \mathrm{mL})$ at 0.05 OD600 and grown at $37{ }^{\circ} \mathrm{C}$ with shaking $(250 \mathrm{rpm})$. Once cell density reached $0.4-0.6(2-4 \mathrm{~h}$ post-induction), protein expression was induced with $1 \mathrm{mM}$ IPTG. Cultures were then grown $18 \mathrm{~h}$ at $20{ }^{\circ} \mathrm{C}$ with shaking $(250 \mathrm{rpm})$ to avoid the formation of inclusion bodies. Cells were centrifuged $\left(6000 \mathrm{x} \mathrm{g}, 20 \mathrm{~min}, 4^{\circ} \mathrm{C}\right)$ and pellets either resuspended in $30 \mathrm{~mL}$ loading buffer $(20 \mathrm{mM}$ Tris $\mathrm{pH} 8.0,300 \mathrm{mM}$ $\mathrm{NaCl}, 10 \mathrm{mM}$ imidazole) or stored at $-80{ }^{\circ} \mathrm{C}$.

Recombinant His 6 -tagged proteins were isolated using a prepacked $1 \mathrm{~mL} \mathrm{Ni}{ }^{2+}$-NTA column (HisTrap Excel, GE Healthcare). To remove loosely bound proteins, the column was washed with $50 \mathrm{mM}$ imidazole until $280 \mathrm{~nm}$ absorbance stabilized. His $_{6}$-tagged protein was eluted utilizing a linear imidazole gradient up to $250 \mathrm{mM}$. Chromatography steps were conducted at $1 \mathrm{~mL} / \mathrm{min}$ with an ÄKTA Pure FPLC system (GE Healthcare). Successful protein expression was confirmed by a band shift in whole cell lysate in Laemmli buffer and $0.05 \%$ 2-mercaptoethanol on a BioRad Criterion Stain-free 4-20\% gradient SDS-PAGE. The gel was UV-activated for $2 \mathrm{~min}$ before imaging on a ProteinSimple FluorChem E system.

Mass spectrometry. SpyCatcher S35C, 2G10-SpyTag scFv, and SpyCatcher-SpyTag scFv conjugate masses were determined by matrix-assisted laser desorption ionization time-of-flight mass spectrometry (MALDI-TOF MS). The matrix solution was prepared by dissolving $10 \mathrm{mg}$ of sinapic acid in $1 \mathrm{~mL}$ of $50 \%$ $\mathrm{CH}_{3} \mathrm{CN}$ and $0.1 \%$ TFA in distilled water. Each protein stock solution (10 to $40 \mu \mathrm{M}$ in $50 \mathrm{mM} \mathrm{NH}_{4} \mathrm{HCO}_{3}$ ) was mixed with the matrix solution in a 1:1 (v/v) ratio. Then, $2 \mu \mathrm{L}$ of each of these mixtures was loaded onto the MALDI plate and dried at atmospheric pressure. Mass spectrometric analyses of crystallized mixtures were conducted on a MALDI TOF/TOF TF4800 (AB SCIEX) mass spectrometer.

Nanoparticle-SpyCatcher conjugation. To generate QDSpyCatcher conjugates, PAOA-encapsulated QDs $(2 \mu \mathrm{M}, 200 \mu \mathrm{L})$ in $100 \mathrm{mM}$ HEPES, $\mathrm{pH} 7.8$, were combined with $\mathrm{SM}(\mathrm{PEG})_{2}(100$ $\mathrm{mM}, 50 \mu \mathrm{L})$ in DMSO. The reaction was mixed at room temperature for $30 \mathrm{~min}$. The mixture was diluted to $4 \mathrm{~mL}$ with 100 $\mathrm{mM}$ HEPES, $\mathrm{pH}$ 7.0, and excess reagents were removed by centrifugal dialysis (Amicon Ultra-4, $100 \mathrm{kDa}$ MWCO), washing with $3 \times 4 \mathrm{~mL}$ of HEPES buffer. An aliquot of SpyCatcher-S35C protein $(200 \mu \mathrm{M}, 100 \mu \mathrm{L})$ was added to a $1.5 \mathrm{~mL}$ low proteinbinding centrifuge tube, the QDs were added, and the reaction was mixed overnight at $4^{\circ} \mathrm{C}$ on a rotary mixer. The reaction mixture was diluted to $4 \mathrm{~mL}$ with $100 \mathrm{mM}$ HEPES, $\mathrm{pH} \mathrm{7.5,} \mathrm{and} \mathrm{excess}$ SpyCatcher protein was removed by centrifugal dialysis (Amicon Ultra-4, $100 \mathrm{kDa}$ MWCO), washing with 4 x $4 \mathrm{~mL}$ of buffer. The retentate was diluted to $400 \mu \mathrm{L}$ in HEPES buffer, and the QDprotein conjugate was stored at $4^{\circ} \mathrm{C}$.

For disulfide conjugated UCNP-SpyCatcher, $50 \mu \mathrm{L}$ of $100 \mathrm{nM}$ PMAO-encapsulated UCNPs were diluted to $400 \mu \mathrm{L}$ with $100 \mathrm{mM}$ HEPES, pH 7.2. Separately, an aliquot of S35C SpyCatcher (200 $\mu \mathrm{M}, 100 \mu \mathrm{L}$ ) was desalted on a Biospin-6 Desalting Column (Bio$\mathrm{Rad}$ ) and further washed by centrifugal dialysis (Amicon Ultra-4, 3 $\mathrm{kDa} \mathrm{MWCO}$ ), washing with $3 \times 4 \mathrm{~mL}$ of HEPES buffer to remove all TCEP storage buffer. The retentate was diluted to $100 \mu \mathrm{L}$ in a $1.5 \mathrm{~mL}$ low protein-binding centrifuge tube, the UCNPs were added, and the reaction was mixed overnight at $4{ }^{\circ} \mathrm{C}$ on a rotary mixer. The reaction mixture was diluted to $4 \mathrm{~mL}$ with $100 \mathrm{mM}$ HEPES, pH 7.5, and excess SpyCatcher was removed by spin dialysis (Amicon Ultra-4, $100 \mathrm{kDa}$ MWCO), washing with 4 x 4 $\mathrm{mL}$ of buffer. The retentate was diluted to $400 \mu \mathrm{L}$ in HEPES buffer, and the UCNP-SpyCatcher conjugate was stored at $4{ }^{\circ} \mathrm{C}$.

Nanoparticle characterization. To determine the size of assynthesized nanocrystals, a dilute dispersion of nanocrystals in hexane was drop cast onto an ultrathin carbon film on lacey carbon support, 400 mesh copper TEM grid (Ted Pella) and dried in a fume hood. Images were collected on a Gemini Ultra-55 Analytical Field Emission Scanning Electron Microscope (Zeiss) in dark-field transmission mode under $30 \mathrm{kV}$ accelerating voltage or on a JEOL $2100-\mathrm{F}$ in HAADF mode under $200 \mathrm{kV}$ accelerating voltage. Diameters for 100 random nanoparticles were manually designated in ImageJ and a distribution was plotted. To determine the size of aqueous nanoparticles, dispersions were diluted to $20 \mathrm{nM}$ in 100 mM HEPES, pH 7.8 for PAOA-encapsulated nanoparticles, and in 100 mM HEPES, pH 7.0, for PMAO-encapsulated and SpyCatcherfunctionalized nanoparticles. The dispersions were sonicated for 30 min prior to measurement. Diameters were measured by dynamic light scattering using a Malvern Zetasizer with typical count rates of 150 kilocounts per second. Data were collected for $60 \mathrm{sec}$ each in 5 separate runs and fits using Malvern Zetasizer software to a volume-weighted size distribution of hydrodynamic diameter.

SpyCatcher quantification on NP surfaces. Tryptophan fluorescence was used to quantify SpyCatcher on nanoparticle surfaces. Emission spectra of UCNPs were taken under $270 \mathrm{~nm}$ excitation prior to and after SpyCatcher conjugation, with difference curves showing a Trp peak at $340 \mathrm{~nm}$. A calibration curve was generated of known concentrations of purified SpyCatcher, to determine SpyCatcher:UCNP stoichiometry.

To follow the disulfide exchange of S35C SpyCatcher onto the 
nanoparticle surface, the absorption signature of the leaving group (pyridine-2-thione) was measured at $343 \mathrm{~nm}$ in a plate reader as a function of time. The concentration of pyridine-2thione was determined from this absorbance and its extinction coefficient $\left(8,080 \mathrm{M}^{-1} \mathrm{~cm}^{-1}\right)$, and a ratio with the nanoparticle concentration defined the number of SpyCatcher proteins exchanged per nanoparticle.

scFv antibody conjugation and characterization. In order to generate the final QD-Ab conjugate, SpyCatcher-coated QDs (100 $\mu \mathrm{l}, 1 \mu \mathrm{M}, 100$ pmoles $)$ and SpyTag-2G10 antibody $(8.9 \mu \mathrm{l}, 22.6 \mu \mathrm{M}$, 201 pmoles, $\sim 2 \mathrm{x}$ excess) were gently mixed overnight and used without further purification. Ab to nanoparticle stoichiometries were tested by varying the volume of added SpyTag-scFv solution. To verify the presence of $A b$ on the nanoparticle surface, fluorescence spectra were taken under $270 \mathrm{~nm}$ excitation prior to and after conjugation, with the difference curve showing a Trp peak at $\sim 340 \mathrm{~nm}$. A calibration curve was generated of known concentrations of purified SpyTag-scFv, and the difference curve peak was used to determine the concentration of $\mathrm{Ab}$ conjugated to the nanoparticle. The final UCNP-Ab conjugate was prepared by mixing SpyCatcher-coated UCNPs $(200 \mu \mathrm{l}, 25 \mathrm{nM}, 5 \mathrm{pmol})$ and SpyTag-scFv $(10 \mu \mathrm{l}, 5 \mu \mathrm{M}, 50 \mathrm{pmol})$ overnight without further purification. $\mathrm{scFv}$-UCNP conjugates were sterilized with $0.22-\mu \mathrm{m}$ filters before addition to cells.

Cell culture. MDA-MB-231 cells were maintained in tissue culture polystyrene dishes (Corning) at $37{ }^{\circ} \mathrm{C}$ in a $5 \% \mathrm{CO}_{2}$ atmosphere in Dulbecco's modified Eagle's medium (DMEM, Sigma) containing 10\% fetal bovine serum (FBS, Gibco) and 1\% penicillin-streptomycin solution (Life Technologies).

Cell labeling and microscopy. Cells were grown in an 8-well chamber slide $(\mu$-Slide 8 Well, IbiTreat, Polymer No. 1.5 and thickness of $180 \mu \mathrm{m}$ ) to $>80 \%$ confluency. For QD imaging: media was aspirated and the wells were washed with 2 x $500 \mu \mathrm{L}$ DMEM without phenol red. QD constructs were diluted to $10 \mathrm{nM}$ in DMEM without phenol red and added to the cells. After $1 \mathrm{~h}$ at $37^{\circ} \mathrm{C}$ in an incubator, cells were washed $1 \mathrm{x}$ with $500 \mu \mathrm{L}$ PBS $+10 \mathrm{mM}$ glucose. The cells were then incubated in a $5 \mu \mathrm{g} / \mathrm{mL}$ solution of AlexaFluor488-WGA (ThermoFisher) in PBS + glucose at room temperature for $10 \mathrm{~min}$, and they were then washed 3 times with $500 \mu \mathrm{L}$ PBS + glucose. Fresh PBS + glucose was added, and the cells were imaged by confocal microscopy. Confocal images of the focal plane at the chamber interface were obtained using an inverted Zeiss LSM710 system with a 1.4 NA $63 x$ Apochromat oil immersion objective. QDs were excited by a $405 \mathrm{~nm}$ diode laser with an MBS-458/514 main dichroic beam splitter, and emission was collected from $605-690 \mathrm{~nm}$. AlexaFluor488 was excited with a $488 \mathrm{~nm}$ diode laser with an MBS-488/594 main dichroic beam splitter, and emission was collected from $495-575 \mathrm{~nm}$.

For UCNP imaging: media was aspirated and the wells were washed with $3 \times 500 \mu \mathrm{L}$ PBST (PBS $+0.1 \%(w / w)$ of TWEEN $\left.{ }^{\circledR} 20\right)$. The cells were pre-incubated for $5 \mathrm{~min}$ at $13{ }^{\circ} \mathrm{C}$ with $400 \mu \mathrm{L}$ of PBST supplemented with $1 \%(w / w)$ BSA and $300 \mathrm{mM}$ glycine. UCNP constructs were added to obtain a final concentration of 5 $\mathrm{nM}$ and maintained for $30 \mathrm{~min}$ at room temperature. In the last 5 min, $3 \mu \mathrm{L}$ of CellMask Orange plasma membrane stain (ThermoFisher) at 50x in PBS was added to the mixture. The solution was aspirated and the well was washed 5 times with PBST. Opti-MEM without phenol red and supplemented with $10 \%(v / v)$ FBS were added and the cells were imaged by time-lapse confocal microscopy at $37{ }^{\circ} \mathrm{C}$. Confocal images of the focal plane at the chamber interface were obtained using an inverted Zeiss LSM710 system with a 40x/1.2NA Apochromat water immersion objective. UCNPs were excited by a $980 \mathrm{~nm}$ diode laser $(500 \mathrm{~mW})$ at maximum intensity reflected by a dichroic beam splitter MBS$760+$. The pinhole was adjusted to 2.7 Airy units and section thickness of $0.7 \mu \mathrm{m}$ to obtain an optimal compromise of emission detection and image resolution. The UCNP images were recorded from 380 to $750 \mathrm{~nm}$ with 1200 Maximum Gain and 15x Digital Gain which provided maximum upconverted emission without detectable autofluorescence under $980 \mathrm{~nm}$ excitation. The lipophilic membrane stain (CellMask Orange) was excited with a $561 \mathrm{~nm}$ diode laser $(20 \mathrm{~mW})$ at $0.2 \%$ of maximum intensity and reflected by MBS-488/561 dichroic beam splitter. The dye emission was collected from 575 to $700 \mathrm{~nm}$ using 900 Maximum Gain and 1x Digital Gain combined with a pinhole set to 1.0 Airy units and section thickness of $1.0 \mu \mathrm{m}$. Each confocal image was collected at scan speed of $177.32 \mu \mathrm{sec}$. The detection time was slowed to the limit of the Zeiss 710LSM confocal due to the long UCNP decay times. Other parameters like $512 \times 512$ pixel resolution, scan area, 16-bit dynamic range, $0.23 \mu \mathrm{m}$ pixel size, 1 line step, mode line bidirectional and two-frame averaging provided optimal compromise between image resolution and detection time. Bright-field images of MDA-MB-231 cells were captured using the brightfield mode of Zeiss 710 LSM with X-Cite 120Q light source, AxioCam MRm camera, $100 \mathrm{~ms}$ acquisition times, and $1388 \times 1040$-pixel resolution.

Confocal images and data processing. ImageJ (Fiji $)^{56}$ was used to analyze the 16-bit images such as adjusting brightness, contrast and image offset. Membranes and intracellular ROIs of individual cells were selected manually. Six cells were selected for the semiquantitative analysis of uPAR-UCNP internalization. The histograms from the ROIs were obtained in the ImageJ (FIJI) and pixel values lower than 3600 counts were selected as background noise. OriginPro (OriginLab) was used to analyze the data. The ratios of intracellular to membrane integrated intensities are average results of 6 cells showed as the mean value \pm standard error of the mean. Time-lapse videos were created from the individual images in RGB format.

\section{ACKNOWLEDGEMENTS}

We thank Dr. Cheryl Tajon for preliminary immunoconjugation experiments and Dr. Behzad Rad for technical support. This work was supported by National Institutes of Health awards R01NS096317 (BEC) and P50AI150476 (CSC). Work at the Molecular Foundry was supported by the Director, Office of Science, Office of Basic Energy Sciences, Division of Materials Sciences and Engineering, of the U.S. Department of Energy under Contract No. DE-AC02$05 \mathrm{CH} 11231$.

\section{AUTHOR INFORMATION}

*Corresponding Author: becohen@1bl.gov

ॠCCSP and VRM contributed equally to this work

\section{Competing Financial Interests}

The authors declare no competing financial interests.

\section{Funding Sources}

US National Institutes of Health

US Department of Energy

\section{REFERENCES}

(1) Freise, A. C.; Wu, A. M. In Vivo Imaging with Antibodies and Engineered Fragments. Mol. Immunol. 2015, 67 (2 Pt A), 142-152. https://doi.org/10.1016/j.molimm.2015.04.001.

(2) Specht, E. A.; Braselmann, E.; Palmer, A. E. A Critical and Comparative Review of Fluorescent Tools for Live-Cell Imaging. Annu. Rev. Physiol. 2017, 79 (1), 93-117. https://doi.org/10.1146/annurev-physiol-022516-034055.

(3) Basu, K.; Green, E. M.; Cheng, Y.; Craik, C. S. Why 
Recombinant Antibodies - Benefits and Applications. Curr. Opin. Biotechnol. 2019, $20, \quad 153-158$ https://doi.org/10.1016/j.copbio.2019.01.012.

(4) Wu, A. M.; Senter, P. D. Arming Antibodies: Prospects and Challenges for Immunoconjugates. Nat. Biotechnol. 2005, 23 (9), 1137-1146. https://doi.org/10.1038/nbt1141.

(5) Rathore, A. S.; Sarker, A.; Gupta, R. D. Recent Developments Toward Antibody Engineering and Affinity Maturation. Protein Pept. Lett. 2018, $25 \quad$ (10), 886-896. https://doi.org/10.2174/0929866525666180925142757.

(6) Saphire, E. O.; Parren, P. W.; Pantophlet, R.; Zwick, M. B.; Morris, G. M.; Rudd, P. M.; Dwek, R. A.; Stanfield, R. L.; Burton, D. R.; Wilson, I. A. Crystal Structure of a Neutralizing Human IGG against HIV-1: A Template for Vaccine Design. Science 2001, 293 (5532), 1155-1159. https://doi.org/10.1126/science.1061692.

(7) Agarwal, P.; van der Weijden, J.; Sletten, E. M.; Rabuka, D.; Bertozzi, C. R. A Pictet-Spengler Ligation for Protein Chemical Modification. Proc. Natl. Acad. Sci. U. S. A. 2013, 110 (1), 46-51. https://doi.org/10.1073/pnas.1213186110.

(8) Kudirka, R.; Barfield, R. M.; McFarland, J.; Albers, A. E.; de Hart, G. W.; Drake, P. M.; Holder, P. G.; Banas, S.; Jones, L. C.; Garofalo, A. W.; Rabuka, D. Generating Site-Specifically Modified Proteins via a Versatile and Stable Nucleophilic Carbon Ligation. Chem. Biol. 2015, 22 (2), 293-298. https://doi.org/10.1016/j.chembiol.2014.11.019.

(9) Shen, B.-Q.; Xu, K.; Liu, L.; Raab, H.; Bhakta, S.; Kenrick, M.; Parsons-Reponte, K. L.; Tien, J.; Yu, S.-F.; Mai, E.; Li, D.; Tibbitts, J.; Baudys, J.; Saad, O. M.; Scales, S. J.; McDonald, P. J.; Hass, P. E.; Eigenbrot, C.; Nguyen, T.; Solis, W. A.; et al. Conjugation Site Modulates the in Vivo Stability and Therapeutic Activity of AntibodyDrug Conjugates. Nat. Biotechnol. 2012, 30 (2), 184-189. https://doi.org/10.1038/nbt.2108.

(10) Shrestha, D.; Bagosi, A.; Szöllösi, J.; Jenei, A. Comparative Study of the Three Different Fluorophore Antibody Conjugation Strategies. Anal. Bioanal. Chem. 2012, 404 (5), 1449-1463. https://doi.org/10.1007/s00216-012-6232-z.

(11) Szabó, Á.; Szendi-Szatmári, T.; Ujlaky-Nagy, L.; Rádi, I.; Vereb, G.; Szöllösi, J.; Nagy, P. The Effect of Fluorophore Conjugation on Antibody Affinity and the Photophysical Properties of Dyes. $\begin{array}{llllll}\text { Biophys. } & \text { J. } & \text { 2018, } & 114 & \text { (3), } & 688-700\end{array}$ https://doi.org/10.1016/j.bpj.2017.12.011.

(12) Chudasama, V.; Maruani, A.; Caddick, S. Recent Advances in the Construction of Antibody-Drug Conjugates. Nat. Chem. 2016, 8 (2), 114-119. https://doi.org/10.1038/nchem.2415.

(13) Medintz, I. L.; Uyeda, H. T.; Goldman, E. R.; Mattoussi, H. Quantum Dot Bioconjugates for Imaging, Labelling and Sensing. Nat. Mater. 2005, 4 (6), 435-446. https://doi.org/10.1038/nmat1390.

(14) Barat, B.; Sirk, S. J.; McCabe, K. E.; Li, J.; Lepin, E. J.; Remenyi, R.; Koh, A. L.; Olafsen, T.; Gambhir, S. S.; Weiss, S.; Wu, A. M. Cys-Diabody Quantum Dot Conjugates (ImmunoQdots) for Cancer Marker Detection. Bioconjug. Chem. 2009, 20 (8), 1474-1481. https://doi.org/10.1021/bc800421f.

(15) Wichner, S. M.; Mann, V. R.; Powers, A. S.; Segal, M. A.; Mir, M.; Bandaria, J. N.; DeWitt, M. A.; Darzacq, X.; Yildiz, A.; Cohen, B. E. Covalent Protein Labeling and Improved Single-Molecule Optical Properties of Aqueous CdSe/CdS Quantum Dots. ACS Nano 2017, 11 (7), 6773-6781. https://doi.org/10.1021/acsnano.7b01470.

(16) Thal, L. B.; Mann, V. R.; Sprinzen, D.; McBride, J. R.; Reid, K. R.; Tomlinson, I. D.; McMahon, D. G.; Cohen, B. E.; Rosenthal, S. J. Ligand-Conjugated Quantum Dots for Fast Sub-Diffraction Protein Tracking in Acute Brain Slices. Biomaterials Science 2020, 8 (3), 837 845. https://doi.org/10.1039/c9bm01629e.

(17) Wu, S.; Han, G.; Milliron, D. J.; Aloni, S.; Altoe, V.; Talapin, D. V.; Cohen, B. E.; Schuck, P. J. Non-Blinking and Photostable Upconverted Luminescence from Single LanthanideDoped Nanocrystals. Proc. Natl. Acad. Sci. U. S. A. 2009, 106 (27), 10917-10921. https://doi.org/10.1073/pnas.0904792106.

(18) Nam, S. H.; Bae, Y. M.; Park, Y. I.; Kim, J. H.; Kim, H. M.; Choi, J. S.; Lee, K. T.; Hyeon, T.; Suh, Y. D. Long-Term Real-Time Tracking of Lanthanide Ion Doped Upconverting Nanoparticles in Living Cells. Angew. Chem. Int. Ed Engl. 2011, 50 (27), 6093-6097. https://doi.org/10.1002/anie.201007979.

(19) Tian, B.; Fernandez-Bravo, A.; Najafiaghdam, H.; Torquato N. A.; Altoe, M. V. P.; Teitelboim, A.; Tajon, C. A.; Tian, Y.; Borys, N. J.; Barnard, E. S.; Anwar, M.; Chan, E. M.; Schuck, P. J.; Cohen, B. E. Low Irradiance Multiphoton Imaging with Alloyed Lanthanide Nanocrystals. Nat. Commun. 2018, 9 (1), 3082. https://doi.org/10.1038/s41467-018-05577-8.

(20) Liang, L.; Feng, Z.; Zhang, Q.; Cong, T. D.; Wang, Y.; Qin, X.; Yi, Z.; Ang, M. J. Y.; Zhou, L.; Feng, H.; Xing, B.; Gu, M.; Li, X.; Liu, X. Continuous-Wave Near-Infrared Stimulated-Emission Depletion Microscopy Using Downshifting Lanthanide Nanoparticles. Nat. Nanotechnol. 2021. https://doi.org/10.1038/s41565-021-00927-y.

(21) Algar, W. R.; Prasuhn, D. E.; Stewart, M. H.; Jennings, T. L.; Blanco-Canosa, J. B.; Dawson, P. E.; Medintz, I. L. The Controlled Display of Biomolecules on Nanoparticles: A Challenge Suited to Bioorthogonal Chemistry. Bioconjug. Chem. 2011, 22 (5), 825-858. https://doi.org/10.1021/bc200065z.

(22) Wegner, K. D.; Jin, Z.; Lindén, S.; Jennings, T. L.; Hildebrandt, N. Quantum-Dot-Based Förster Resonance Energy Transfer Immunoassay for Sensitive Clinical Diagnostics of LowVolume Serum Samples. ACS Nano 2013, 7 (8), 7411-7419. https://doi.org/10.1021/nn403253y.

(23) Li, L.; Fierer, J. O.; Rapoport, T. A.; Howarth, M. Structural Analysis and Optimization of the Covalent Association between SpyCatcher and a Peptide Tag. J. Mol. Biol. 2014, 426 (2), 309-317. https://doi.org/10.1016/j.jmb.2013.10.021.

(24) Miyanabe, K.; Akiba, H.; Kuroda, D.; Nakakido, M.; Kusano-Arai, O.; Iwanari, H.; Hamakubo, T.; Caaveiro, J. M. M.; Tsumoto, K. Intramolecular H-Bonds Govern the Recognition of a Flexible Peptide by an Antibody. J. Biochem. 2018, 164 (1), 65-76. https://doi.org/10.1093/jb/mvy032.

(25) Francis, J. E.; Mason, D.; Lévy, R. Evaluation of Quantum Dot Conjugated Antibodies for Immunofluorescent Labelling of Cellular Targets. Beilstein J. Nanotechnol. 2017, 8, 1238-1249. https://doi.org/10.3762/bjnano.8.125.

(26) Tajima, N.; Takai, M.; Ishihara, K. Significance of Antibody Orientation Unraveled: Well-Oriented Antibodies Recorded High Binding Affinity. Anal. Chem. 2011, 83 (6), 1969-1976. https://doi.org/10.1021/ac1026786.

(27) Qiu, X.; Wegner, K. D.; Wu, Y.-T.; van Bergen en Henegouwen, P. M. P.; Jennings, T. L.; Hildebrandt, N. Nanobodies and Antibodies for Duplexed EGFR/HER2 Immunoassays Using Terbium-to-Quantum Dot FRET. Chem. Mater. 2016, 28 (22), 82568267. https://doi.org/10.1021/acs.chemmater.6b03198.

(28) Bhuckory, S.; Mattera, L.; Wegner, K. D.; Qiu, X.; Wu, Y.T.; Charbonnière, L. J.; Reiss, P.; Hildebrandt, N. Direct Conjugation of Antibodies to the $\mathrm{ZnS}$ Shell of Quantum Dots for FRET Immunoassays with Low Picomolar Detection Limits. Chem. Commun. (Camb.) 2016, $52 \quad$ (100), 14423-14425. https://doi.org/10.1039/c6cc08835j.

(29) Léger, C.; Yahia-Ammar, A.; Susumu, K.; Medintz, I. L.; Urvoas, A.; Valerio-Lepiniec, M.; Minard, P.; Hildebrandt, N. Picomolar Biosensing and Conformational Analysis Using Artificial Bidomain Proteins and Terbium-to-Quantum Dot Förster Resonance Energy Transfer. ACS Nano 2020, 14 (5), 5956-5967. https://doi.org/10.1021/acsnano.0c01410.

(30) Wu, Y.-T.; Qiu, X.; Lindbo, S.; Susumu, K.; Medintz, I. L.; Hober, S.; Hildebrandt, N. Quantum Dot-Based FRET Immunoassay for HER2 Using Ultrasmall Affinity Proteins. Small 2018, 14 (35), e1802266. https://doi.org/10.1002/smll.201802266.

(31) Annio, G.; Jennings, T. L.; Tagit, O.; Hildebrandt, N. Sensitivity Enhancement of Förster Resonance Energy Transfer Immunoassays by Multiple Antibody Conjugation on Quantum Dots. Bioconjug. Chem. 2018, 29 (6), 2082-2089. https://doi.org/10.1021/acs.bioconjchem.8b00296.

(32) Agarwal, P.; Bertozzi, C. R. Site-Specific Antibody-Drug Conjugates: The Nexus of Bioorthogonal Chemistry, Protein Engineering, and Drug Development. Bioconjug. Chem. 2015, 26 (2), 176-192. https://doi.org/10.1021/bc5004982.

(33) Zakeri, B.; Fierer, J. O.; Celik, E.; Chittock, E. C.; SchwarzLinek, U.; Moy, V. T.; Howarth, M. Peptide Tag Forming a Rapid 
Covalent Bond to a Protein, through Engineering a Bacterial Adhesin. Proc. Natl. Acad. Sci. U. S. A. 2012, 109 (12), E690-E697. https://doi.org/10.1073/pnas.1115485109.

(34) Keeble, A. H.; Turkki, P.; Stokes, S.; Khairil, I. N.; Rahikainen, R.; Hytönen, V. P.; Howarth, M. Approaching Infinite Affinity through Engineering of Peptide-Protein Interaction. Proc. Natl. Acad. Sci. U. S. A. 2019, 116 (52), 26523-26533. https://doi.org/10.1073/pnas.1909653116.

(35) Charrier, M.; Li, D.; Mann, V.; Yun, L.; Jani, S.; Rad, B.; Cohen, B. E.; Ashby, P. D.; Ryan, K.; Ajo-Franklin, C. M. Engineering the S-Layer of Caulobacter Crescentus as a Foundation for Stable, High-Density, 2D Living Materials. ACS Synth. Biol. 2018. 8 (1), 181190. https://doi.org/10.1021/acssynbio.8b00448.

(36) Mann, V. R.; Manea, F.; Borys, N. J.; Ajo-Franklin, C. M.; Cohen, B. E. Controlled and Stable Patterning of Diverse Inorganic Nanocrystals on Crystalline Two-Dimensional Protein Arrays. Biochemistry 2021, $60 \quad$ (13), 1063-1074. https://doi.org/10.1021/acs.biochem.1c00032.

(37) Mauro, C. D.; Pesapane, A.; Formisano, L.; Rosa, R.; D'Amato, V.; Ciciola, P.; Servetto, A.; Marciano, R.; Orsini, R. C.; Monteleone, F.; Zambrano, N.; Fontanini, G.; Servadio, A.; Pignataro, G.; Grumetto, L.; Lavecchia, A.; Bruzzese, D.; Iaccarino, A.; Troncone, G.; Veneziani, B. M.; et al. Urokinase-Type Plasminogen Activator Receptor (UPAR) Expression Enhances Invasion and Metastasis in RAS Mutated Tumors. Sci. Rep. 2017, 7 (1), 9388. https://doi.org/10.1038/s41598-017-10062-1.

(38) Duriseti, S.; Goetz, D. H.; Hostetter, D. R.; LeBeau, A. M.; Wei, Y.; Craik, C. S. Antagonistic Anti-Urokinase Plasminogen Activator Receptor (UPAR) Antibodies Significantly Inhibit UPARMediated Cellular Signaling and Migration. J. Biol. Chem. 2010, 285 (35), 26878-26888. https://doi.org/10.1074/jbc.M109.077677.

(39) LeBeau, A. M.; Duriseti, S.; Murphy, S. T.; Pepin, F.; Hann, B.; Gray, J. W.; VanBrocklin, H. F.; Craik, C. S. Targeting UPAR with Antagonistic Recombinant Human Antibodies in Aggressive Breast Cancer. Cancer Res. 2013, 73 (7), 2070-2081. https://doi.org/10.1158/0008-5472.CAN-12-3526.

(40) Smith, H. W.; Marshall, C. J. Regulation of Cell Signalling by UPAR. Nat. Rev. Mol. Cell Biol. 2010, 11 (1), 23-36. https://doi.org/10.1038/nrm2821.

(41) LeBeau, A. M.; Sevillano, N.; King, M. L.; Duriseti, S.; Murphy, S. T.; Craik, C. S.; Murphy, L. L.; VanBrocklin, H. F. Imaging the Urokinase Plasminongen Activator Receptor in Preclinical Breast Cancer Models of Acquired Drug Resistance. Theranostics 2014, 4 (3), 267-279. https://doi.org/10.7150/thno.7323.

(42) Jo, M.; Eastman, B. M.; Webb, D. L.; Stoletov, K.; Klemke, R.; Gonias, S. L. Cell Signaling by Urokinase-Type Plasminogen Activator Receptor Induces Stem Cell-Like Properties in Breast Cancer Cells. Cancer Res. 2010, 70 (21), 8948-8958. https://doi.org/10.1158/0008-5472.can-10-1936.

(43) Tajon, C. A.; Yang, H.; Tian, B.; Tian, Y.; Ercius, P.; Schuck, P. J.; Chan, E. M.; Cohen, B. E. Photostable and Efficient Upconverting Nanocrystal-Based Chemical Sensors. Opt. Mater. 2018, 84, 345-353. https://doi.org/10.1016/j.optmat.2018.07.031

(44) Mann, V. R.; Powers, A. S.; Tilley, D. C.; Sack, J. T.; Cohen, B. E. Azide-Alkyne Click Conjugation on Quantum Dots by Selective Copper Coordination. ACS Nano 2018, 12 (5), 4469-4477. https://doi.org/10.1021/acsnano.8b00575.

(45) Di Corato, R.; Quarta, A.; Piacenza, P.; Ragusa, A.; Figuerola, A.; Buonsanti, R.; Cingolani, R.; Manna, L.; Pellegrino, T. Water Solubilization of Hydrophobic Nanocrystals by Means of Poly(Maleic Anhydride-Alt-1-Octadecene). J. Mater. Chem. 2008, 18 (17), 1991-1996. https://doi.org/10.1039/b717801h.

(46) Myers, D. A.; Murdoch, W. J.; Villemez, C. L. ProteinPeptide Conjugation by a Two-Phase Reaction. Biochem. J 1985, 227 (1), 343. https://doi.org/10.1042/bj2270343.

(47) Sgier, D.; Zuberbuehler, K.; Pfaffen, S.; Neri, D. Isolation and Characterization of an Inhibitory Human Monoclonal Antibody Specific to the Urokinase-Type Plasminogen Activator, UPA. Protein Eng. Des. Sel. 2010, 23 (4), 261-269. https://doi.org/10.1093/protein/gzp089.

(48) Jacquemet, G.; Baghirov, H.; Georgiadou, M.; Sihto, H.;
Peuhu, E.; Cettour-Janet, P.; He, T.; Perälä, M.; Kronqvist, P.; Joensuu, H.; Ivaska, J. L-Type Calcium Channels Regulate Filopodia Stability and Cancer Cell Invasion Downstream of Integrin Signalling. Nat. Commun. 2016, 7, 13297. https://doi.org/10.1038/ncomms13297.

(49) Franchi, M.; Piperigkou, Z.; Riti, E.; Masola, V.; Onisto, M.; Karamanos, N. K. Long Filopodia and Tunneling Nanotubes Define New Phenotypes of Breast Cancer Cells in 3D Cultures. Matrix Biol Plus 2020, 6-7, 100026. https://doi.org/10.1016/j.mbplus.2020.100026.

(50) Czekay, R.-P.; Kuemmel, T. A.; Orlando, R. A.; Farquhar, M. G. Direct Binding of Occupied Urokinase Receptor (UPAR) to LDL Receptor-Related Protein Is Required for Endocytosis of UPAR and Regulation of Cell Surface Urokinase Activity. Mol. Biol. Cell 2001, 12 (5), 1467-1479. https://doi.org/10.1091/mbc.12.5.1467.

(51) Harel, E. T.; Drake, P. M.; Barfield, R. M.; Lui, I.; FarrJones, S.; Van't Veer, L.; Gartner, Z. J.; Green, E. M.; Lourenço, A. L.; Cheng, Y.; Hann, B. C.; Rabuka, D.; Craik, C. S. Antibody-Drug Conjugates Targeting the Urokinase Receptor (UPAR) as a Possible Treatment of Aggressive Breast Cancer. Antibodies (Basel) 2019, 8 (4). https://doi.org/10.3390/antib8040054.

(52) Ostrowski, A. D.; Chan, E. M.; Gargas, D. J.; Katz, E. M.; Han, G.; Schuck, P. J.; Milliron, D. J.; Cohen, B. E. Controlled Synthesis and Single-Particle Imaging of Bright, Sub-10 Nm Lanthanide-Doped Upconverting Nanocrystals. ACS Nano 2012, 6 (3), 2686-2692. https://doi.org/10.1021/nn3000737.

(53) Gargas, D. J.; Chan, E. M.; Ostrowski, A. D.; Aloni, S.; Altoe, M. V. P.; Barnard, E. S.; Sanii, B.; Urban, J. J.; Milliron, D. J.; Cohen, B. E.; Schuck, P. J. Engineering Bright Sub-10-nm Upconverting Nanocrystals for Single-Molecule Imaging. Nat. Nanotechnol. $\quad 2014, \quad 9 \quad$ (4), $300-305$. https://doi.org/10.1038/nnano.2014.29.

(54) Teitelboim, A.; Tian, B.; Garfield, D. J. Energy Transfer Networks within Upconverting Nanoparticles Are Complex Systems with Collective, Robust, and History-Dependent Dynamics. J. Phys. $\begin{array}{lllll}\text { Chem. } & C & \mathbf{2 0 1 9}, & 123 & \text { (4), 2678-2689. }\end{array}$ https://doi.org/10.1021/acs.jpcc.9b00161.

(55) Jia, H.-R.; Wang, H.-Y.; Yu, Z.-W.; Chen, Z.; Wu, F.-G. Long-Time Plasma Membrane Imaging Based on a Two-Step Synergistic Cell Surface Modification Strategy. Bioconjug. Chem. 2016, 27 (3), 782-789. https://doi.org/10.1021/acs.bioconjchem.6b00003.

(56) Schindelin, J.; Arganda-Carreras, I.; Frise, E.; Kaynig, V.; Longair, M.; Pietzsch, T.; Preibisch, S.; Rueden, C.; Saalfeld, S.; Schmid, B.; Tinevez, J.-Y.; White, D. J.; Hartenstein, V.; Eliceiri, K.; Tomancak, P.; Cardona, A. Fiji: An Open-Source Platform for Biological-Image Analysis. Nat. Methods 2012, 9 (7), 676-682. https://doi.org/10.1038/nmeth.2019.

(57) Chivers, C. E.; Crozat, E.; Chu, C.; Moy, V. T.; Sherratt, D. J.; Howarth, M. A Streptavidin Variant with Slower Biotin Dissociation and Increased Mechanostability. Nat. Methods 2010, 7 (5), 391-393. https://doi.org/10.1038/nmeth.1450.

(58) Dennler, P.; Fischer, E.; Schibli, R. Antibody Conjugates: From Heterogeneous Populations to Defined Reagents. Antibodies (Basel) 2015, 4 (3), 197-224. https://doi.org/10.3390/antib4030197.

(59) Aragnol, D.; Leserman, L. D. Immune Clearance of Liposomes Inhibited by an Anti-Fc Receptor Antibody in Vivo. Proc. Natl. Acad. Sci. U. S. A. 1986, 83 (8), 2699-2703. https://doi.org/10.1073/pnas.83.8.2699.

(60) Goldman, E. R.; Anderson, G. P.; Tran, P. T.; Mattoussi, H.; Charles, P. T.; Mauro, J. M. Conjugation of Luminescent Quantum Dots with Antibodies Using an Engineered Adaptor Protein to Provide New Reagents for Fluoroimmunoassays. Anal. Chem. 2002, 74 (4), 841-847. https://doi.org/10.1021/ac010662m.

(61) Ma, L.; Geng, J.; Kolossov, V. L.; Han, Z.; Pei, Y.; Lim, S. J.; Kilian, K. A.; Smith, A. M. Antibody Self-Assembly Maximizes Cytoplasmic Immunostaining Accuracy of Compact Quantum Dots. Chem. Mater. 2021, 33 (13), 4877-4889. https://doi.org/10.1021/acs.chemmater.1c00164.

(62) Albrecht, H.; Burke, P. A.; Natarajan, A.; Xiong, C.-Y.; Kalicinsky, M.; DeNardo, G. L.; DeNardo, S. J. Production of Soluble ScFvs with C-Terminal-Free Thiol for Site-Specific Conjugation or 
Stable Dimeric ScFvs on Demand. Bioconjug. Chem. 2004, 15 (1), 16 26. https://doi.org/10.1021/bc030018+.

(63) Nuñez-Prado, N.; Compte, M.; Harwood, S.; ÁlvarezMéndez, A.; Lykkemark, S.; Sanz, L.; Álvarez-Vallina, L. The Coming of Age of Engineered Multivalent Antibodies. Drug Discov. Today 2015, 20 (5), 588-594. https://doi.org/10.1016/j.drudis.2015.02.013.

(64) Hashad, R. A.; Lange, J. L.; Tan, N. C. W.; Alt, K.; Hagemeyer, C. E. Engineering Antibodies with C-Terminal SortaseMediated Modification for Targeted Nanomedicine. Methods Mol. Biol. 2019, 2033, 67-80. https://doi.org/10.1007/978-1-4939-965446.

(65) Lee, C.; Xu, E. Z.; Liu, Y.; Teitelboim, A.; Yao, K.; Fernandez-Bravo, A.; Kotulska, A. M.; Nam, S. H.; Suh, Y. D.; Bednarkiewicz, A.; Cohen, B. E.; Chan, E. M.; Schuck, P. J. Giant Nonlinear Optical Responses from Photon-Avalanching Nanoparticles. Nature 2021, 589 (7841), 230-235. https://doi.org/10.1038/s41586020-03092-9.

(66) Najafiaghdam, H.; Papageorgiou, E.; Torquato, N. A.; Tian, B.; Cohen, B. E.; Anwar, M. A 25 Micron-Thin Microscope for Imaging Upconverting Nanoparticles with NIR-I and NIR-II Illumination. Theranostics 2019, 9 (26), 8239-8252. https://doi.org/10.7150/thno.37672.

(67) Del Rosal, B.; Jaque, D. Upconversion Nanoparticles for in Vivo Applications: Limitations and Future Perspectives. Methods Appl. Fluoresc. 2019, 7 (2), 022001. https://doi.org/10.1088/20506120/ab029f

(68) Li, X.; Zhao, H.; Ji, Y.; Yin, C.; Li, J.; Yang, Z.; Tang, Y.; Zhang, Q.; Fan, Q.; Huang, W. Lysosome-Assisted Mitochondrial Targeting Nanoprobe Based on Dye-Modified Upconversion Nanophosphors for Ratiometric Imaging of Mitochondrial Hydrogen Sulfide. ACS Appl. Mater. Interfaces 2018, 10 (46), 39544-39556. https://doi.org/10.1021/acsami.8b16818.

(69) Wang, H.; Li, Y.; Yang, M.; Wang, P.; Gu, Y. FRET-Based Upconversion Nanoprobe Sensitized by $\mathrm{Nd} 3+$ for the Ratiometric Detection of Hydrogen Peroxide in Vivo. ACS Appl. Mater. Interfaces 2019, 11 (7), 7441-7449. https://doi.org/10.1021/acsami.8b21549.

(70) Liang, T.; Li, Z.; Wang, P.; Zhao, F.; Liu, J.; Liu, Z. Breaking through the Signal-to-Background Limit of Upconversion Nanoprobes Using a Target-Modulated Sensitizing Switch. J. Am. Chem. Soc. 2018, 140 (44), 14696-14703. https://doi.org/10.1021/jacs.8b07329.

(71) Pasupuleti, N.; Grodzki, A. C.; Gorin, F. Mis-Trafficking of Endosomal Urokinase Proteins Triggers Drug-Induced Glioma Nonapoptotic Cell Death. Mol. Pharmacol. 2015, 87 (4), 683-696. https://doi.org/10.1124/mol.114.096602.

(72) Cortese, K.; Sahores, M.; Madsen, C. D.; Tacchetti, C.; Blasi, F. Clathrin and LRP-1-Independent Constitutive Endocytosis and Recycling of UPAR. PLoS One 2008, 3 (11), e3730. https://doi.org/10.1371/journal.pone.0003730.

(73) Rennick, J. J.; Johnston, A. P. R.; Parton, R. G. Key Principles and Methods for Studying the Endocytosis of Biological and Nanoparticle Therapeutics. Nat. Nanotechnol. 2021, 16 (3), 266-276. https://doi.org/10.1038/s41565-021-00858-8.

(74) Nykjaer, A.; Conese, M.; Christensen, E. I.; Olson, D.; Cremona, O.; Gliemann, J.; Blasi, F. Recycling of the Urokinase Receptor upon Internalization of the UPA:Serpin Complexes. EMBOJ. 1997, 16 (10), 2610-2620. https://doi.org/10.1093/emboj/16.10.2610.

(75) Chan, E. M.; Xu, C.; Mao, A. W.; Han, G.; Owen, J. S.; Cohen, B. E.; Milliron, D. J. Reproducible, High-Throughput Synthesis of Colloidal Nanocrystals for Optimization in Multidimensional Parameter Space. Nano Lett. 2010, 10 (5), 1874-1885. https://doi.org/10.1021/n1100669s. 